\title{
BMJ Global Health Eye care delivery models to improve access to eye care for Indigenous peoples in high- income countries: a scoping review
}

To cite: Burn H, Hamm L, Black J, et al. Eye care delivery models to improve access to eye care for Indigenous peoples in highincome countries: a scoping review. BMJ Global Health 2021;6:e04484. doi:10.1136/ bmjgh-2020-004484

Handling editor Stephanie M Topp

Received 16 November 2020 Revised 28 December 2020 Accepted 20 January 2021

\section{Check for updates}

(C) Author(s) (or their employer(s)) 2021. Re-use permitted under CC BY. Published by BMJ.

${ }^{1}$ International Centre for Eye Health, London School of Hygiene \& Tropical Medicine, London, UK

${ }^{2}$ School of Optometry and Vision Science, Faculty of Medicine and Health Sciences, The University of Auckland, Auckland, New Zealand

${ }^{3}$ School of Optometry and Vision Science, University of New South Wales, Sydney, New South Wales, Australia

${ }^{4}$ General Practice and Primary Healthcare, Faculty of Medicine and Health Sciences, University of Auckland, Auckland, New Zealand

${ }^{5}$ Moorfields Eye Hospital NHS Foundation Trust, London, UK

\section{Correspondence to}

Dr Helen Burn;

helen.burn1@alumni.Ishtm. ac.uk

\section{ABSTRACT}

Purpose Globally, there are $\sim 370$ million Indigenous peoples. Indigenous peoples typically experience worse health compared with non-Indigenous people, including higher rates of avoidable vision impairment. Much of this gap in eye health can be attributed to barriers that impede access to eye care services. We conducted a scoping review to identify and summarise service delivery models designed to improve access to eye care for Indigenous peoples in high-income countries.

Methods Searches were conducted on MEDLINE, Embase and Global Health in January 2019 and updated in July 2020. All study designs were eligible if they described a model of eye care service delivery aimed at populations with over $50 \%$ Indigenous peoples. Two reviewers independently screened titles, abstracts and full-text articles and completed data charting. We extracted data on publication details, study context, service delivery interventions, outcomes and evaluations, engagement with Indigenous peoples and access dimensions targeted. We summarised findings descriptively following thematic analysis

Results We screened 2604 abstracts and 67 studies fulfilled our eligibility criteria. Studies were focused on Indigenous peoples in Australia $(n=45)$, USA $(n=11)$, Canada $(n=7)$, New Zealand $(n=2)$, Taiwan $(n=1)$ and Greenland $(n=1)$. The main disease focus was diabetic retinopathy $(n=30,45 \%)$, followed by 'all eye care' ( $n=16,24 \%)$. Most studies focused on targeted interventions to increase availability of services. Fewer than one-third of studies reported involving Indigenous communities when designing the service. 41 studies reflected on whether the model improved access, but none undertook rigorous evaluation or quantitative assessment.

Conclusions The geographical and clinical scope of service delivery models to improve access to eye care for Indigenous peoples in high-income countries is narrow, with most studies focused on Australia and services for diabetic retinopathy. More and better engagement with Indigenous communities is required to design and implement accessible eye care services.

\section{Key questions}

What is already known?

- Indigenous peoples globally experience worse health outcomes compared with non-Indigenous people including a higher prevalence of avoidable blindness and vision impairment, most commonly due to cataract and refractive error.

- In high-income countries, much of this inequality is a result of lack of access to appropriate eye care services for Indigenous peoples.

What are the new findings?

- There is a narrow range of evidence on how to deliver accessible eye care services for Indigenous peoples in high-income countries.

- The majority of the reports identified in our review were conducted in Australia and focused on teleophthalmology screening for diabetic retinopathy.

- Less than half of all reports described service delivery models that aimed to be culturally appropriate or engage Indigenous communities during service design and implementation.

- The methodological approaches used to describe and evaluate interventions to improve access to eye care could be strengthened to provide more robust evidence on effectiveness.

What do the new findings imply?

- Future research needs a greater geographical scope and should include services to address the leading causes of vision loss in Indigenous peoples: cataract and refractive error.

- The design and evaluation of eye care service delivery models would benefit from consideration of al five dimensions of access (approachability, acceptability, availability, affordability and appropriateness) and more partnership with Indigenous peoples.

\section{INTRODUCTION}

Indigenous peoples are custodians, guardians and practitioners of unique ways of life. ${ }^{1}$ Indigenous peoples have displayed strength 
and persistence in preserving and continuing their culture despite a shared history of violent colonisation and violation of human rights. In 2015, most countries signed up to achieve the Sustainable Development Goals (SDGs) by 2030, with an overarching aim to leave no one behind. ${ }^{2}$ In the 90 countries where Indigenous peoples live, of whom there are an estimated 370 million, they are among the most marginalised and should therefore be a priority group in the SDG era. ${ }^{3}$ The term Indigenous people is used to describe many diverse peoples and cultures. For this review we use the definition of Indigenous peoples provided by the United Nations Permanent Forum on Indigenous Issues (UNPFII). ${ }^{34}$

Indigenous peoples across the globe have poorer health and social outcomes compared with non-Indigenous people, including dying younger, having higher rates of infant mortality and poverty, and lower educational attainment. $^{5}$ The 2015 United Nations report, State of the World's Indigenous Peoples, stated that 'Indigenous peoples' access to adequate health care remains one of the most challenging and complex areas' ${ }^{6}$ While $80 \%$ of Indigenous peoples live in low-income and middleincome countries in Asia, Latin America and Africa, the report recognised that in high-income countries Indigenous peoples experience significant health disadvantage compared with non-Indigenous people as a result of institutionalised discrimination and marginalisation. ${ }^{67}$ For example, in 2012 the median life expectancy for Indigenous Australians was 10 years lower than for non-Indigenous Australians. ${ }^{8}$

One area of concern for Indigenous peoples is eye health. Vision impairment surveys tend not to include subanalysis by Indigeneity, so in many countries the prevalence of vision impairment among Indigenous communities is unknown. ${ }^{9}$ Australia is the only high-income country to have carried out a nationwide survey of the prevalence and causes of vision loss comparing Indigenous and non-Indigenous Australians. The 2016 survey found that the prevalence of vision impairment was 2.8 times greater in Indigenous Australians $(17.7 \%, 95 \%$ CI 14.5 to 21.0) compared with non-Indigenous Australians $(6.4 \%, 95 \%$ CI 5.2 to 7.6$)$ after adjusting for age and gender $(\mathrm{p}<0.001) .{ }^{10}$ Much of this disparity in vision impairment can be attributed to reduced access to eye care services, distrust of health services and a lack of cultural safety and non-clinical support systems. ${ }^{11}$ Indigenous participants had lower prevalence of eye care examinations compared with non-Indigenous participants, with geographical remoteness further reducing the likelihood of having had an eye examination in the past 2 years. ${ }^{12}{ }^{13}$ Canada, the USA and New Zealand have had no nationwide survey of Indigenous eye health, but smaller studies reporting prevalence of vision impairment, blindness or specific ophthalmic conditions have consistently shown a higher burden among Indigenous compared with non-Indigenous communities. ${ }^{14-20}$ Again, access to eye care services is highlighted as a key factor in maintaining this population inequality, for example, eye services not being available in locations with majority Indigenous peoples, the prohibitive cost of travelling to and accessing clinical care, a lack of integrated culturally appropriate eye services and a lack of consistent skills in cultural safety for those delivering care. ${ }^{12} 21$

Strategies to improve access to eye care services for Indigenous peoples must be informed by evidence and include the perspectives of those people currently 'missing out'. This scoping review aims to summarise the existing literature on service delivery models designed to improve access to eye care services for Indigenous peoples. This work fed into the Lancet Global Health Commission on Global Eye Health. ${ }^{22}$

This review is focused on high-income countries and aimed to answer the following questions:

- What is the quantity and the characteristics of published reports describing service delivery models to improve access to eye care for Indigenous peoples in high-income countries?

- What methods and interventions are used by these service delivery models to improve access to eye care?

- What are the current gaps in the literature and what lessons can be learnt regarding models that have been successful in improving access?

We defined eye care service delivery models as any organised programme designed to provide or improve eye care services, ranging from non-specialised primary healthcare to tertiary ophthalmic care. ${ }^{23}$ Our definition of access was guided by the conceptual framework of patient-centred healthcare access by Levesque $e t a l,{ }^{24}$ which emphasises the importance of both the supply and demand sides of healthcare access.

\section{METHODS}

\section{Protocol and registration}

The protocol for this review has been previously published. ${ }^{23}$ We have reported this review following the Preferred Reporting Items for Systematic Reviews and Meta-Analyses for Scoping Reviews guideline. ${ }^{25}$

\section{Patient and public involvement}

It was not feasible to include patient and public engagement in this research.

\section{Eligibility criteria}

Our eligibility criteria were as follows:

- Population: the target population of the service delivery model was Indigenous peoples, as defined by the United Nations. ${ }^{4}$ If the target population was not exclusively Indigenous, we included studies where $50 \%$ or more of the population were Indigenous.

- Intervention: any service delivery model to improve access to eye care. These could include theoretical modelling of a service or a description and/or evaluation of an existing implemented service delivery model. If the report gave a clear description of the service delivery model within the methodology or discussion, it was included even if its primary aim 
was not to describe or evaluate a service delivery model. For example, reports with a primary aim of describing disease prevalence but which also describe an eye service delivery model within the report were included.

- Setting: high-income country (as defined by the World Bank in 2019) ${ }^{26}$

- Comparator: studies with or without a comparator group were included.

- Outcomes: could include any eye service delivery outcome components, for example, number of service users, number of clinical assessments, number of treatments provided, and patient or health worker satisfaction.

- Study design: primary research reports of any study design (qualitative, quantitative and mixed methods studies). We excluded editorials, conference abstracts and posters, systematic reviews and grey literature.

- Other: there was no time limit on publication dates and no language limitations.

\section{Information sources}

On 25 January 2019 an information specialist searched MEDLINE, Embase and Global Health, using the strategy published as a supplementary file with our protocol. ${ }^{23}$ This search was updated on 2 July 2020. All databases were searched from their inception without language limits. We examined the reference lists of all included articles to identify further potentially relevant reports of studies. We also searched the reference lists of systematic reviews that were identified during the searches.

\section{Selection of sources of evidence}

Two reviewers (two of $\mathrm{HB}$, JR, JB, $\mathrm{LH}$ or $\mathrm{AB}$ ) independently screened the titles and abstracts of identified reports to exclude publications that did not meet the inclusion criteria. Full-text articles were retrieved for review if the citation seemed potentially relevant. Two of these reviewers independently assessed the full text of each report against the eligibility criteria. Any discrepancies between the reviewers were resolved by discussion, and a third reviewer was consulted when necessary.

\section{Data charting process}

Two custom data charting forms were developed in Excel: one for studies describing implemented service delivery models in which the model is currently or has been previously applied to a population (eg, an existing spectacle supply programme for Indigenous peoples); and the other for non-implemented model reports which describe wider components of service delivery and access that have not been executed within a population (eg, a discussion of methods to deliver culturally sensitive eye care). Each form was first piloted on five studies by each of $\mathrm{HB}, \mathrm{JR}, \mathrm{JB}, \mathrm{LH}$ and $\mathrm{AB}$, and required amendments were agreed by consensus. Due to the broad scope of the studies included, data charting was an iterative process throughout the review process, with the data charting forms amended as required. Each included study was charted independently by two reviewers. Any discrepancies between the reviewers were resolved by discussion, and a third reviewer was consulted if necessary.

\section{Data items}

For all reports we collected the following data items:

- Publication characteristics: author, title, year of publication, country in which the model was applied and type of model described (implemented service delivery model or non-implemented).

- Context: Indigenous population targeted, eye conditions targeted and clinical service provided.

- Summary of service delivery model described.

For studies describing implemented service delivery models, the following additional data items were extracted:

- Characteristics of service delivery model:

- Indigenous engagement and cultural sensitivity (eg, whether Indigenous peoples were included in service design and implementation, methods to improve cultural sensitivity of services).

- Service delivery inputs identified in the model (eg, human resources, medicines, surgeries, spectacles, facilities, ophthalmic equipment, health information systems).

- Access dimensions from the Levesque model $^{24}$ that were addressed by the model.

- Service delivery outcomes of the model if stated (eg, number of consultations, number of spectacles dispensed, number of surgeries performed, patient satisfaction).

- If the model was evaluated, and summary of the main points from the evaluation.

\section{Synthesis of results}

The quantitative data were summarised using descriptive statistical methods (eg, measures of frequency). Qualitative data were analysed using thematic analysis. For data items on Indigenous engagement and cultural sensitivity, access dimensions and evaluation findings, data from the two data collectors were collated and read through several times for a process of familiarisation and reflection. A coding system was then developed using an iterative process of code development. The codes were then grouped into themes from which key intervention characteristics were identified. For data items on access, key themes were mapped onto the Levesque model of access dimensions. ${ }^{24}$

\section{RESULTS}

\section{Selection of sources of evidence}

We screened 2604 titles and abstracts, of which 250 fulltext articles were subsequently reviewed and 67 reports ultimately included. The 67 reports represented 67 


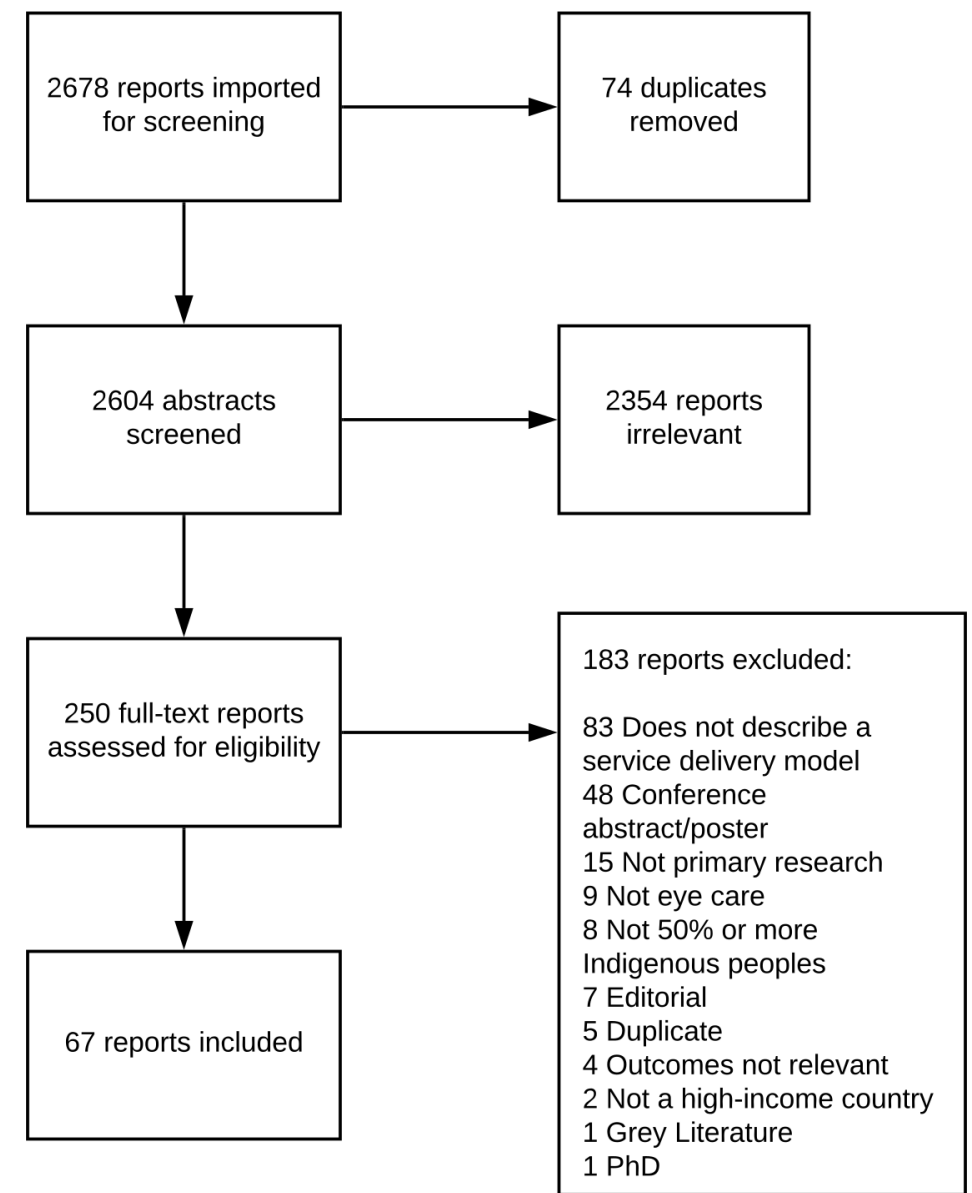

Figure 1 PRISMA flow diagram. PRISMA, Preferred Reporting Items for Systematic Reviews and Meta-Analyses.

separate studies and 63 distinct models as some models were described by more than one paper (figure 1 ).

\section{Characteristics of sources of evidence}

Of the 67 included studies, 50 described an implemented service delivery model (hereafter referred to as implemented models) that is in use, or has been in use, within a population. From these 50 studies, 46 distinct service delivery models were described. A further 17 reports discussed components of service delivery models to increase access to eye care for Indigenous populations without describing an implemented model (hereafter referred to as non-implemented models). Most studies focused on Indigenous peoples in Australia $(n=45,67 \%)$, followed by the USA $(n=11,16 \%)$, Canada $(n=7,10 \%)$, New Zealand $(n=2,3 \%)$, Taiwan $(n=1,2 \%)$ and Greenland $(\mathrm{n}=1,2 \%)$; two-thirds were published after 2010 $(\mathrm{n}=45,67 \%)$ (table 1$)$.

The main disease focus of the studies was diabetic retinopathy $(n=30,45 \%)$, followed by 'all eye care' $(n=16$, $24 \%)$ and trachoma $(\mathrm{n}=11,16 \%)$. Few studies discussed interventions to improve access for patients with cataract, refractive error or glaucoma. The most common clinical services discussed in the literature were screening $(n=29,43 \%)$, 'general eye care' $(n=14,21 \%)$ and surgical services (non-trichiasis) $(\mathrm{n}=5,7 \%)$. Interventions to improve access to optometry, rehabilitation services and health promotion services for Indigenous peoples were less commonly described in the literature (table 1).

\section{Synthesis of results}

Implemented service delivery models

Characteristics of implemented service delivery models

The 46 implemented service delivery models from 50 studies described a range of models to provide eye care to Indigenous peoples. These are summarised in table 2. Almost two-thirds were implemented in Australia $(\mathrm{n}=29 / 46,63 \%)$ and almost half $(\mathrm{n}=21 / 46,46 \%)$ described a teleophthalmology programme, most of which $(n=19 / 21,90 \%)$ were screening programmes for diabetic retinopathy. Most of these $(n=12 / 21,57 \%)$ described integration of teleophthalmology for diabetic eye screening into existing diabetes care in community primary care or Indigenous healthcare clinics in Australia. ${ }^{27-41} \mathrm{~A}$ further six models described mobile teleophthalmology services visiting Indigenous communities in Australia, ${ }^{29} 42$ Canada $^{43}{ }^{44}$ and New Zealand. ${ }^{45}{ }^{46}$ One model described both these approaches and is therefore listed twice. ${ }^{29} \mathrm{In}$ three of these teleophthalmology models Indigenous health workers in Australia were trained to take fundus images. ${ }^{35} 3642$ Two further models from Australia focused on technical aspects of the screening programme, such as addition of optical coherence tomography imaging ${ }^{47}$ and the use of direct ophthalmoscopy compared with fundus 
Table 1 Characteristics of included studies

\begin{tabular}{|c|c|c|c|}
\hline & $\begin{array}{l}\text { Implemented models } \\
\mathrm{n}=50(\%)^{\star}\end{array}$ & $\begin{array}{l}\text { Non-implemented models } \\
\mathrm{n}=17(\%)\end{array}$ & $\begin{array}{l}\text { All reports } \\
\mathrm{N}=67(\%)\end{array}$ \\
\hline \multicolumn{4}{|l|}{ Country which the model applies to } \\
\hline Australia & $31(62)$ & $14(82)$ & $45(67)$ \\
\hline USA & $9(18)$ & $2(12)$ & $11(16)$ \\
\hline Canada & $6(12)$ & $1(6)$ & $7(10)$ \\
\hline New Zealand & $2(4)$ & $0(0)$ & $2(3)$ \\
\hline Greenland & $1(2)$ & $0(0)$ & $1(2)$ \\
\hline Taiwan & $1(2)$ & $0(0)$ & $1(2)$ \\
\hline \multicolumn{4}{|l|}{ Year of publication } \\
\hline Pre-1980 & $2(4)$ & $0(0)$ & $2(3)$ \\
\hline 1980-1989 & $1(2)$ & $0(0)$ & $1(2)$ \\
\hline 1990-1999 & $4(8)$ & $2(12)$ & $6(9)$ \\
\hline 2000-2009 & $12(24)$ & $1(6)$ & $13(19)$ \\
\hline 2010-2020 & $31(62)$ & $14(82)$ & $45(67)$ \\
\hline \multicolumn{4}{|l|}{ Eye disease targeted } \\
\hline Diabetic retinopathy & $26(52)$ & $4(24)$ & $30(45)$ \\
\hline All eye care & $8(16)$ & $8(47)$ & $16(24)$ \\
\hline Trachoma & $9(18)$ & $2(12)$ & $11(16)$ \\
\hline Cataract & $3(6)$ & $1(5)$ & $4(6)$ \\
\hline Refractive error & $2(4)$ & $2(12)$ & $4(6)$ \\
\hline Glaucoma & $1(2)$ & $0(0)$ & $1(1.5)$ \\
\hline Low vision & $1(2)$ & $0(0)$ & $1(1.5)$ \\
\hline \multicolumn{4}{|l|}{ Main clinical service in the model } \\
\hline Screening & $26(52)$ & $3(18)$ & $29(43)$ \\
\hline Non-specific/general & $6(12)$ & $8(47)$ & $14(21)$ \\
\hline Surgery (excluding trichiasis surgery) & $4(2)$ & $1(6)$ & $5(7)$ \\
\hline Optometry & $2(4)$ & $2(12)$ & $4(6)$ \\
\hline Health promotion/training & $2(4)$ & $1(6)$ & $3(4)$ \\
\hline Rehabilitation & $1(2)$ & $0(0)$ & $1(1.5)$ \\
\hline \multicolumn{4}{|l|}{ SAFE for trachoma } \\
\hline Surgery & $4(2)$ & $2(12)$ & $6(9)$ \\
\hline Antibiotics & $4(2)$ & $2(12)$ & $6(9)$ \\
\hline Facial cleanliness & $6(12)$ & $2(12)$ & $8(12)$ \\
\hline Environmental change & $3(6)$ & $2(12)$ & $5(7)$ \\
\hline
\end{tabular}

*Percentage of the total number of studies for each of the three groups.

†Some trachoma reports describe more than one SAFE component.

cameras. $^{48}$ A further model described mobile vision screening for children in Australia (aged 0-16 years) integrated within an existing ear screening programme visiting schools. ${ }^{49}$ Lastly, one model described the use of teleophthalmology to assist in preoperative assessments to reduce the waiting times for cataract surgery. ${ }^{50}$

Beyond integration of teleophthalmology services, nine models described the integration of other eye care services into existing Indigenous primary healthcare. Three models focused on optometry services in the USA $^{51}$ and Australia. ${ }^{52}$ Three described the integration of eye care into comprehensive diabetic services in Australia ${ }^{54}$ and Canada. ${ }^{56}$ One focused specifically on cataract services in Australia, ${ }^{57}$ and two described general eye care programmes in Australia. ${ }^{58} 59$

Another described model was the use of outreach services $(n=5)$. Four papers described outreach to rural and remote locations by optometrists and/or ophthalmologists: one in Taiwan ${ }^{60}$ and three in Australia. ${ }^{61-63}$ One paper described mobile laser surgery for narrow angle glaucoma prevention in Canada. ${ }^{64}$ 


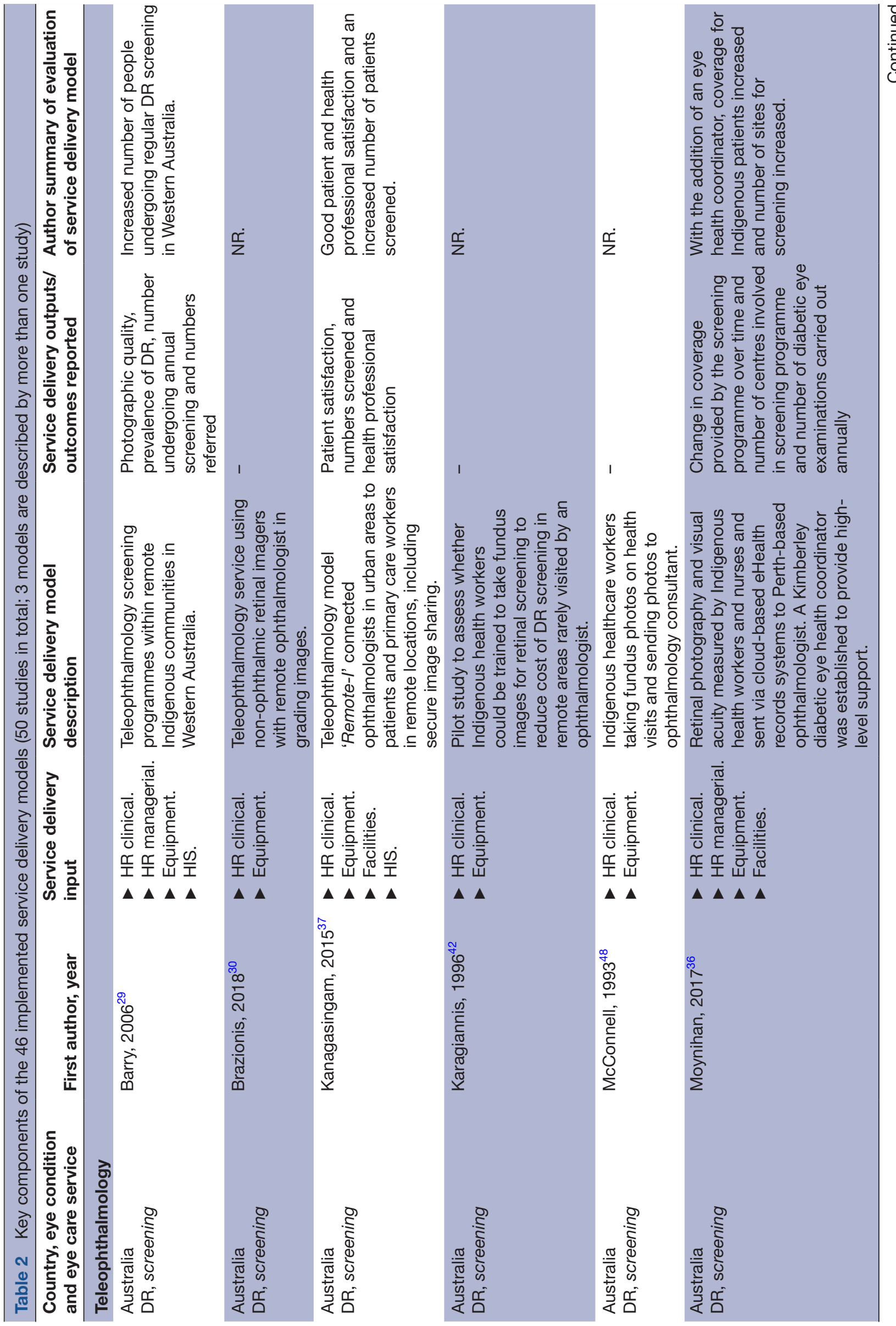

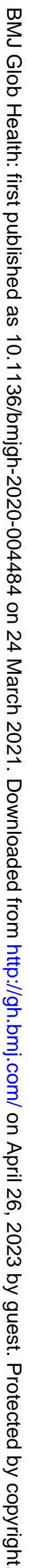




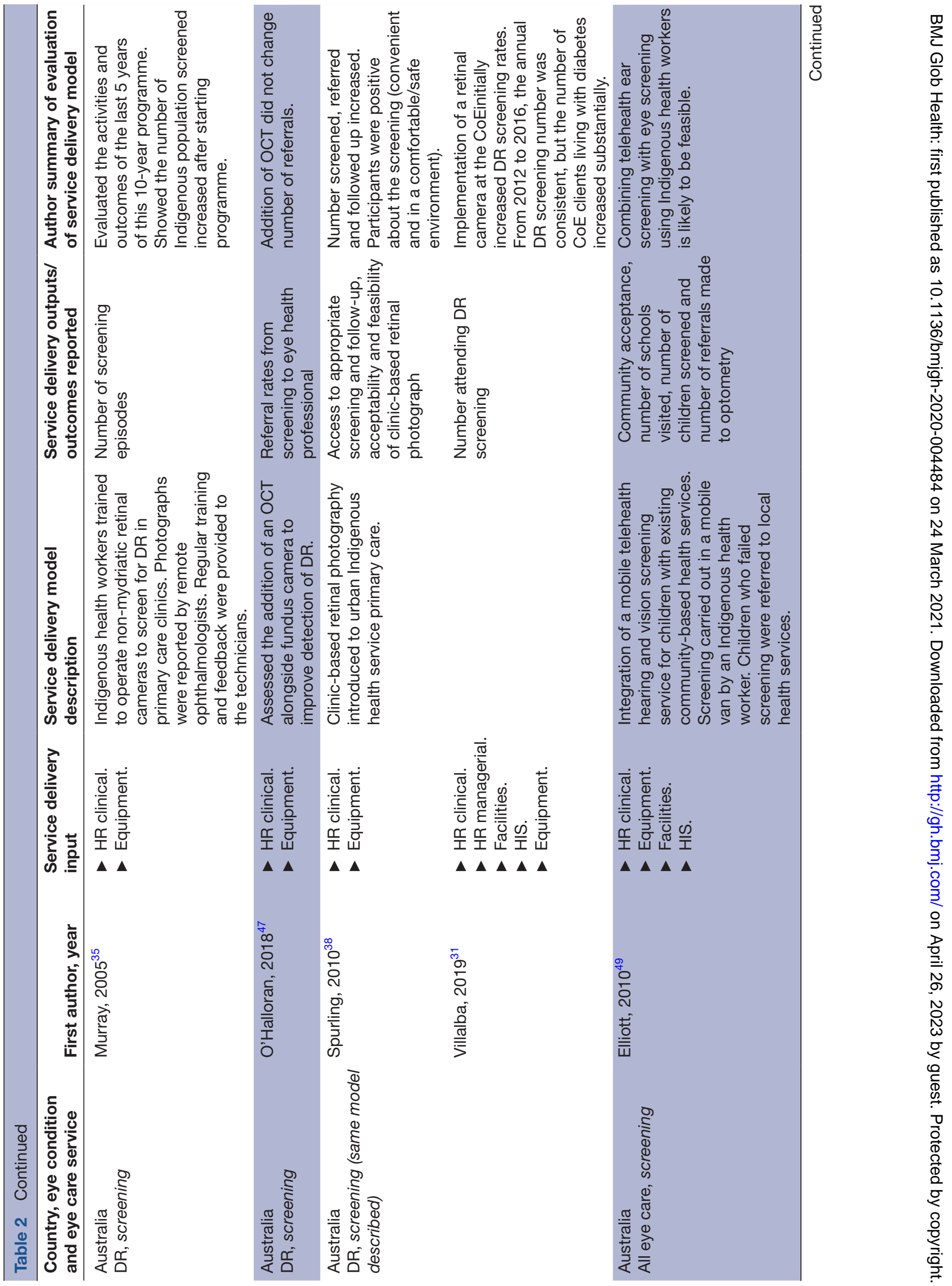




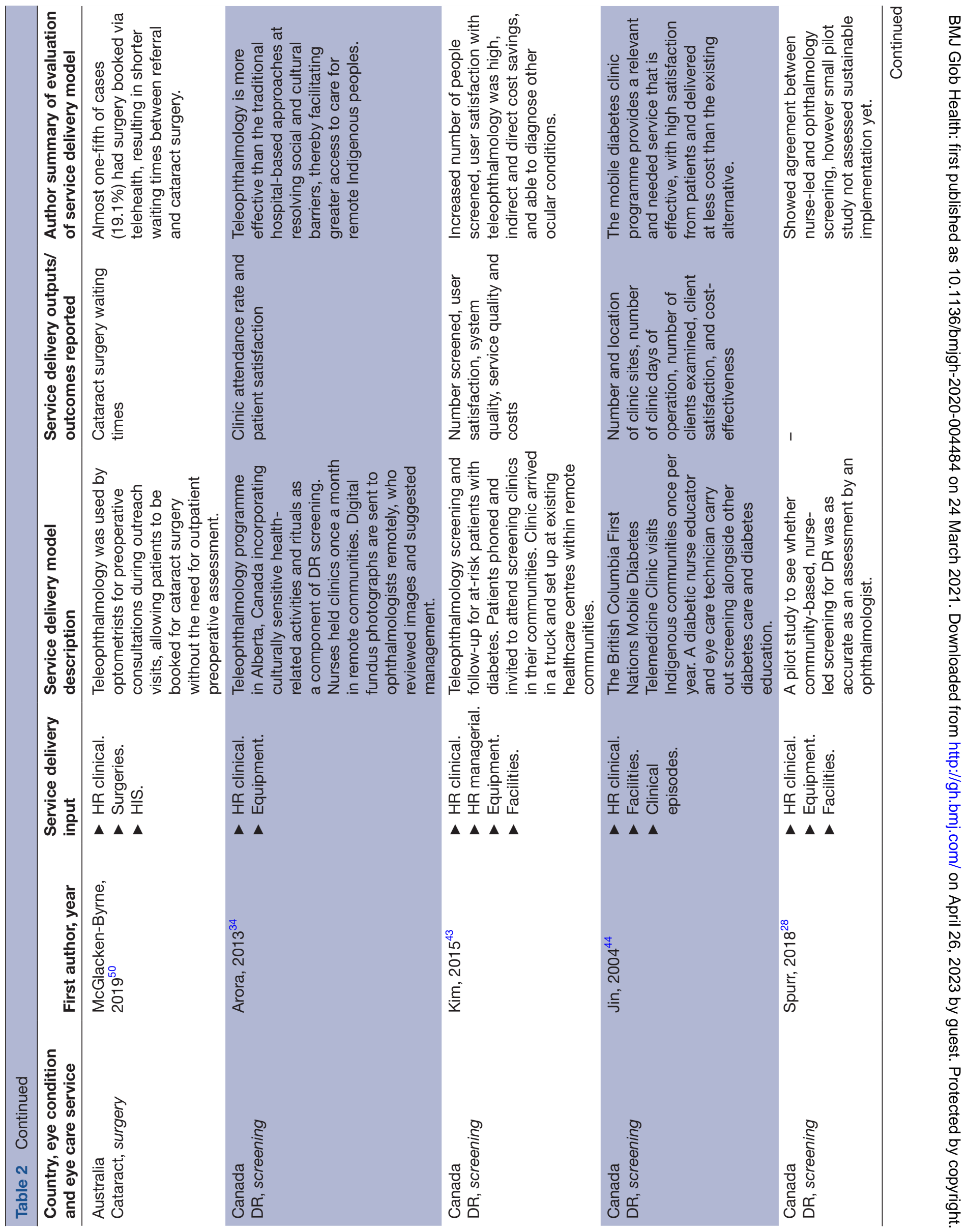




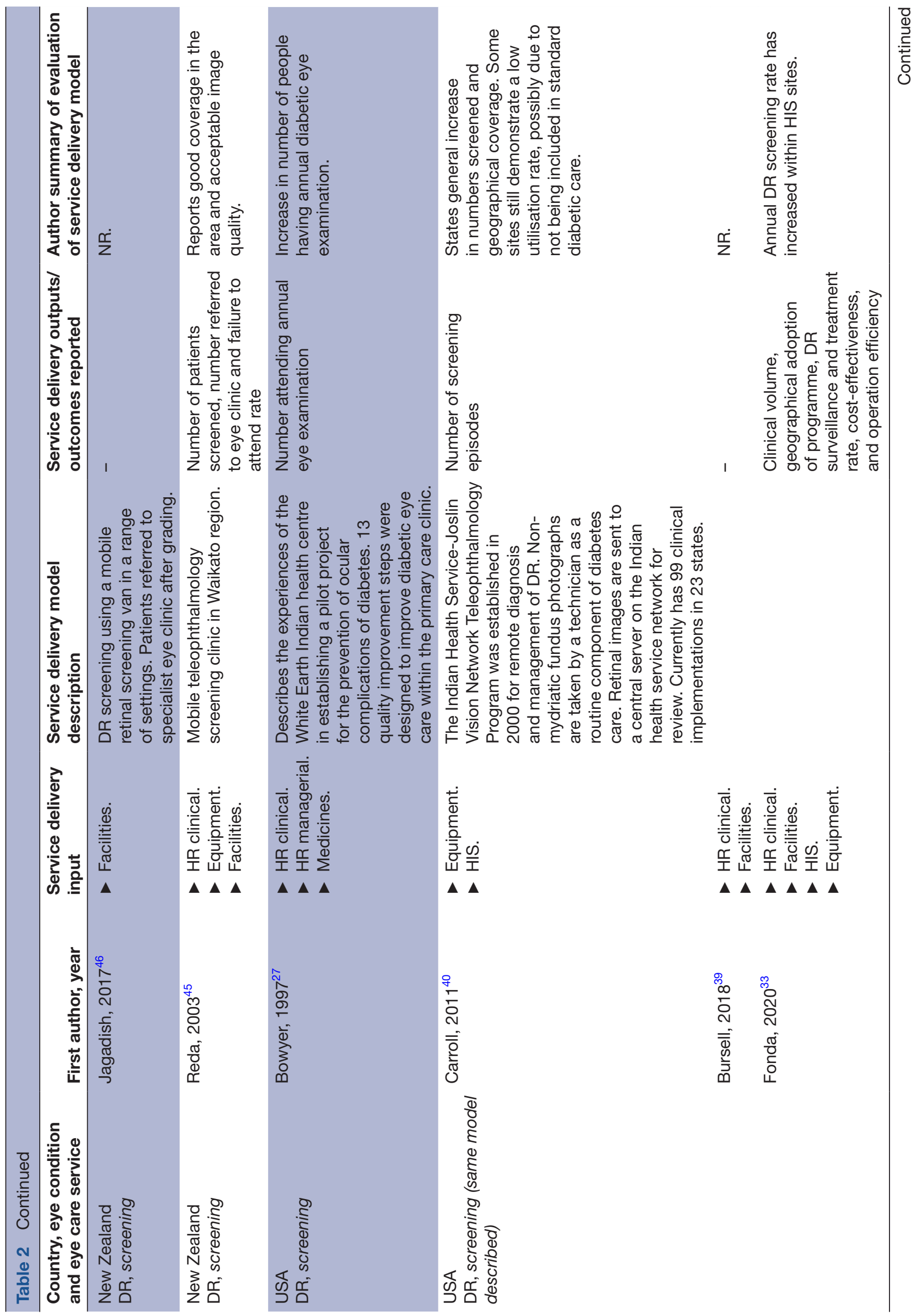




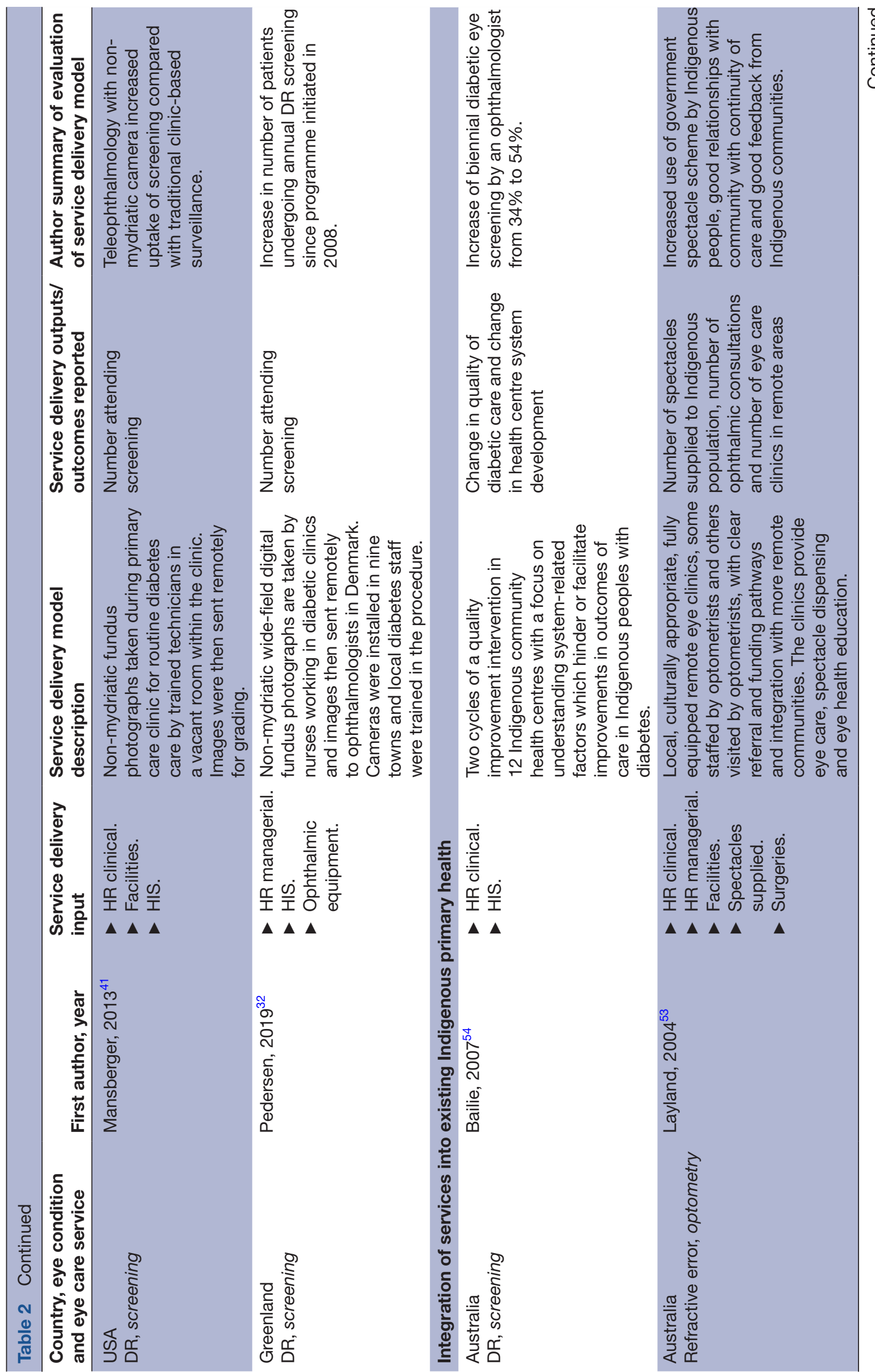




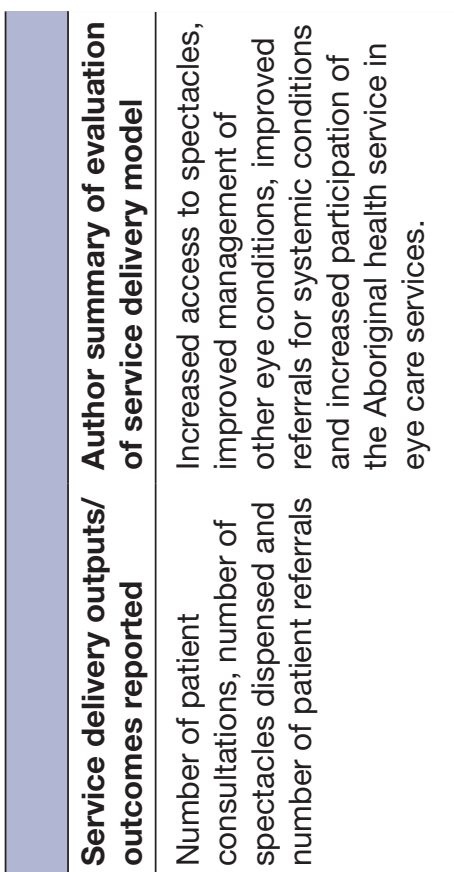

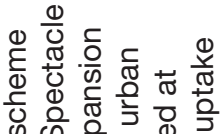

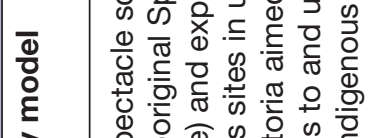

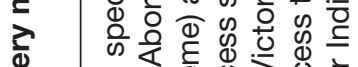

$\stackrel{0}{1}$

ब。

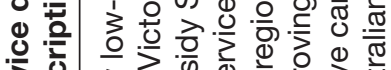

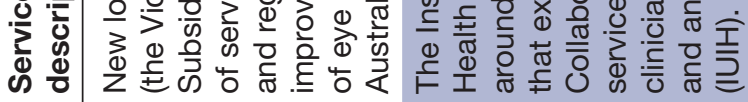

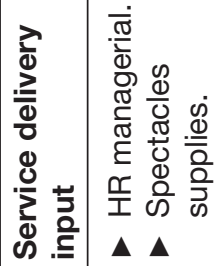

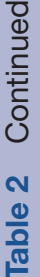
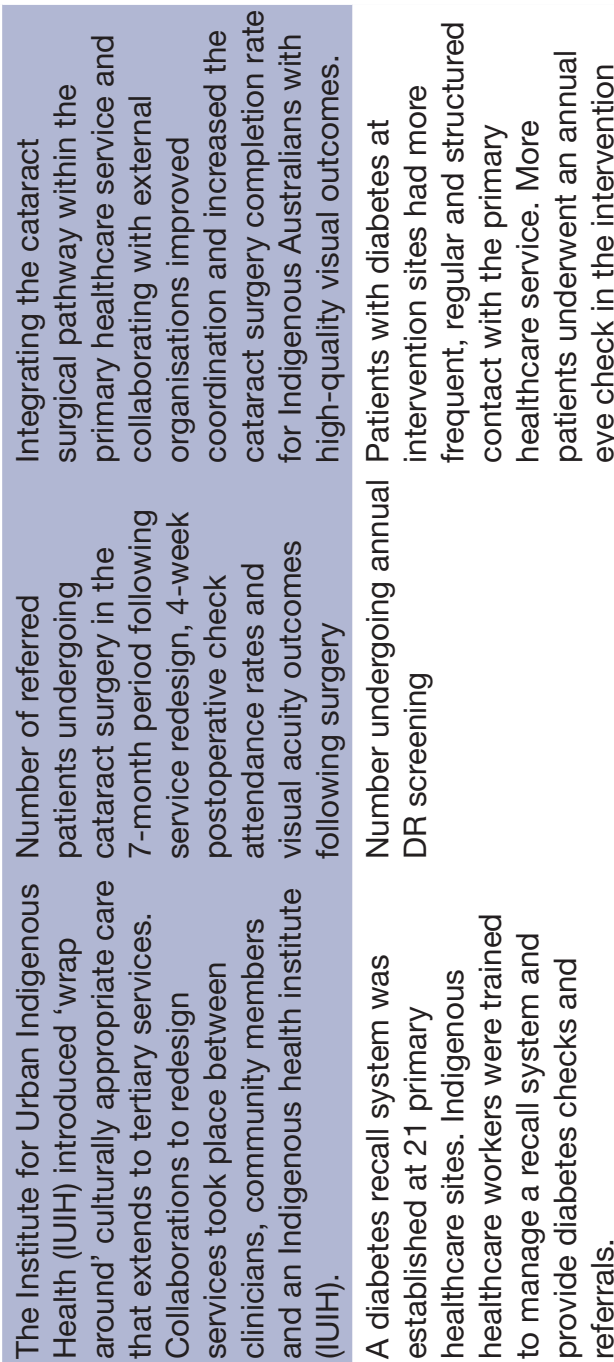

응

응 o

क $3 \pi$

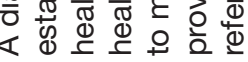
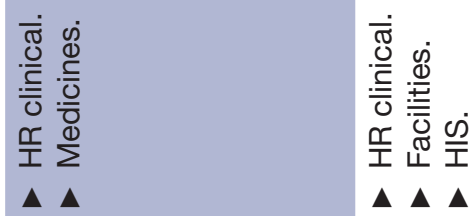

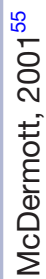

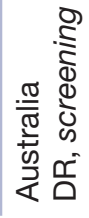

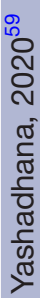

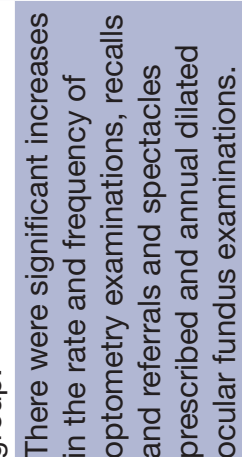

$\stackrel{\infty}{\frac{0}{5}}$

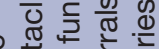

过

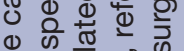

बक कि के

엉 웅 을 중

这

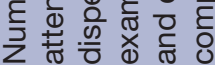

की

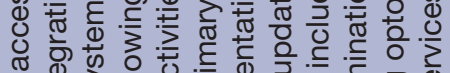

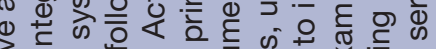

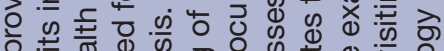

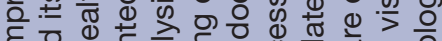

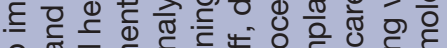

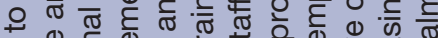

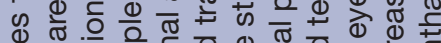

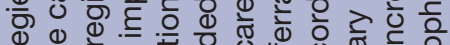
๘

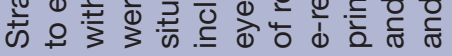
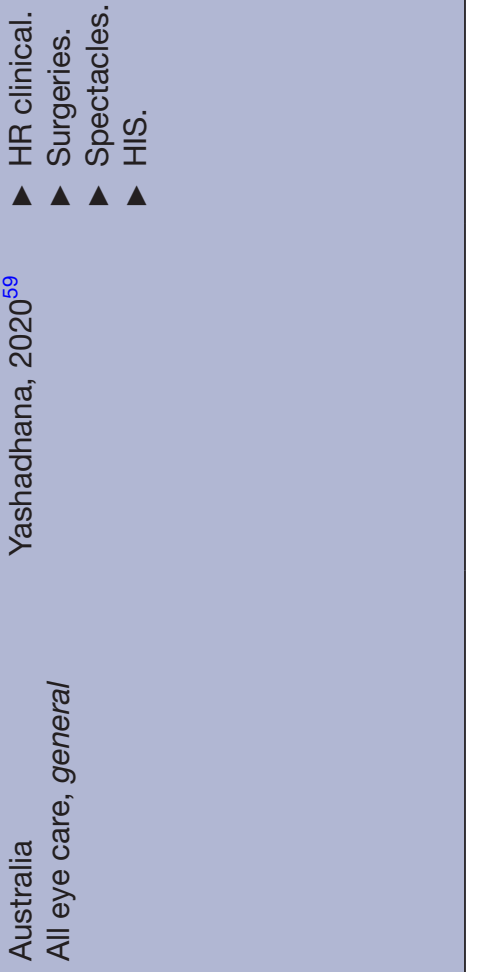


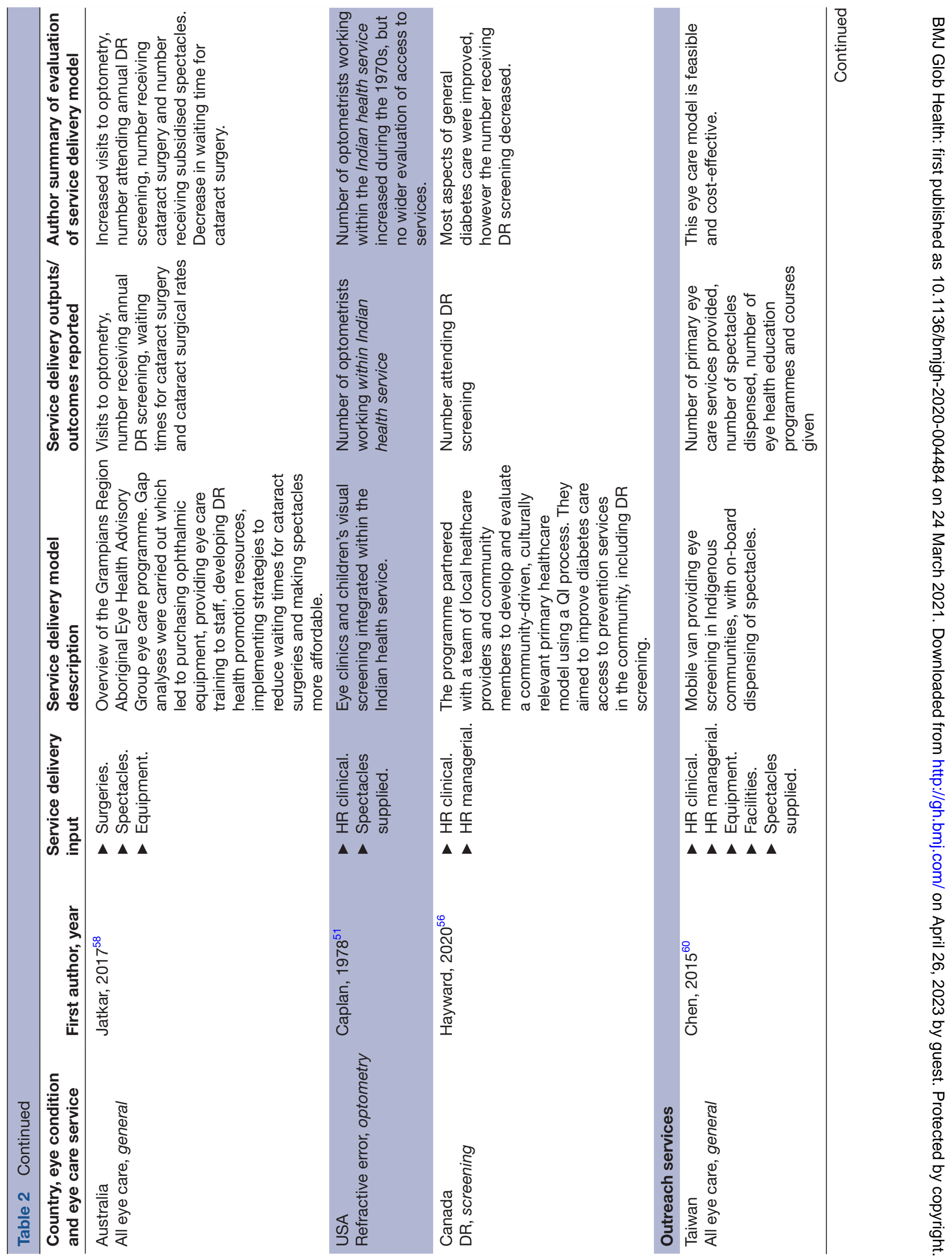




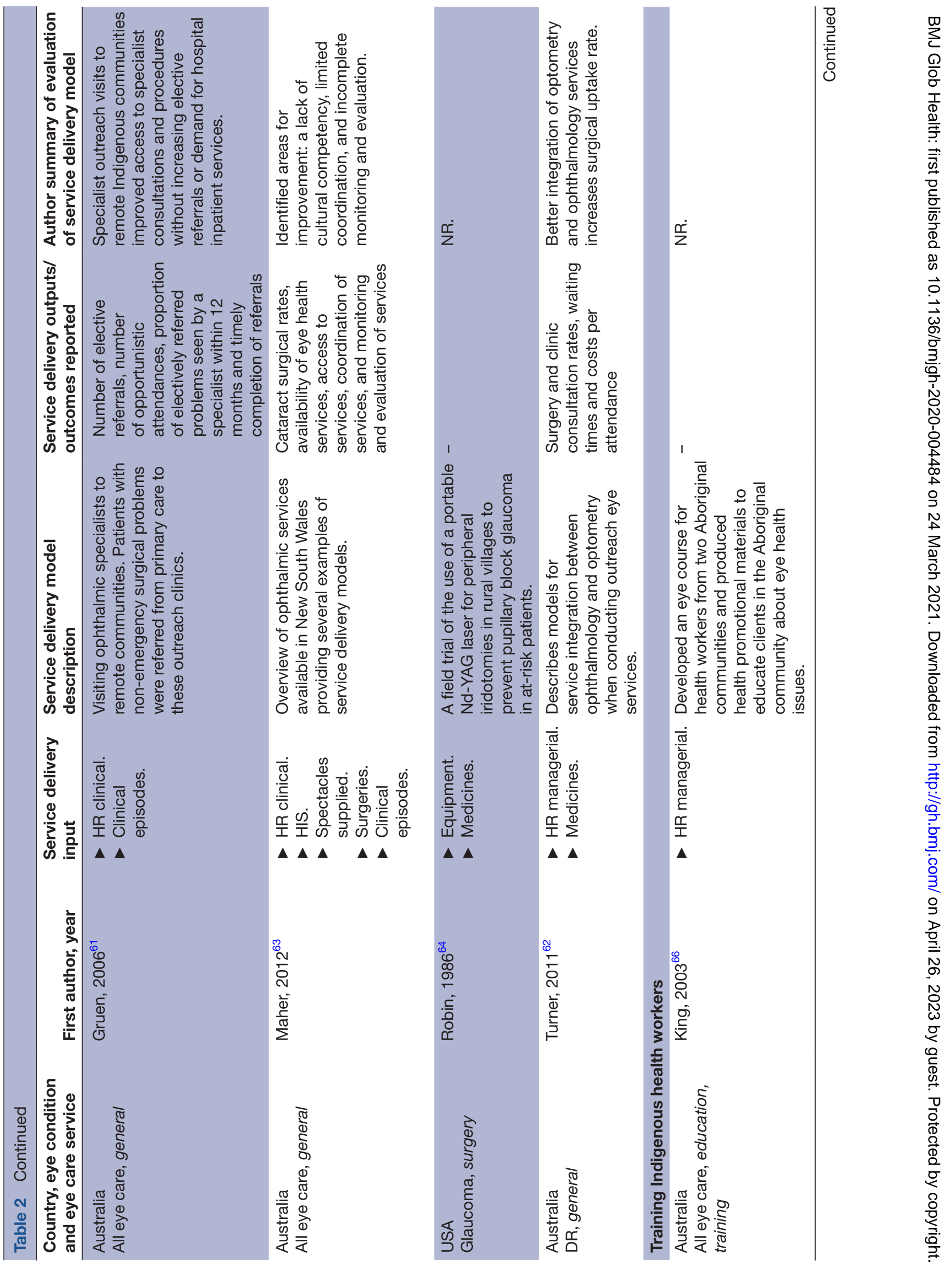




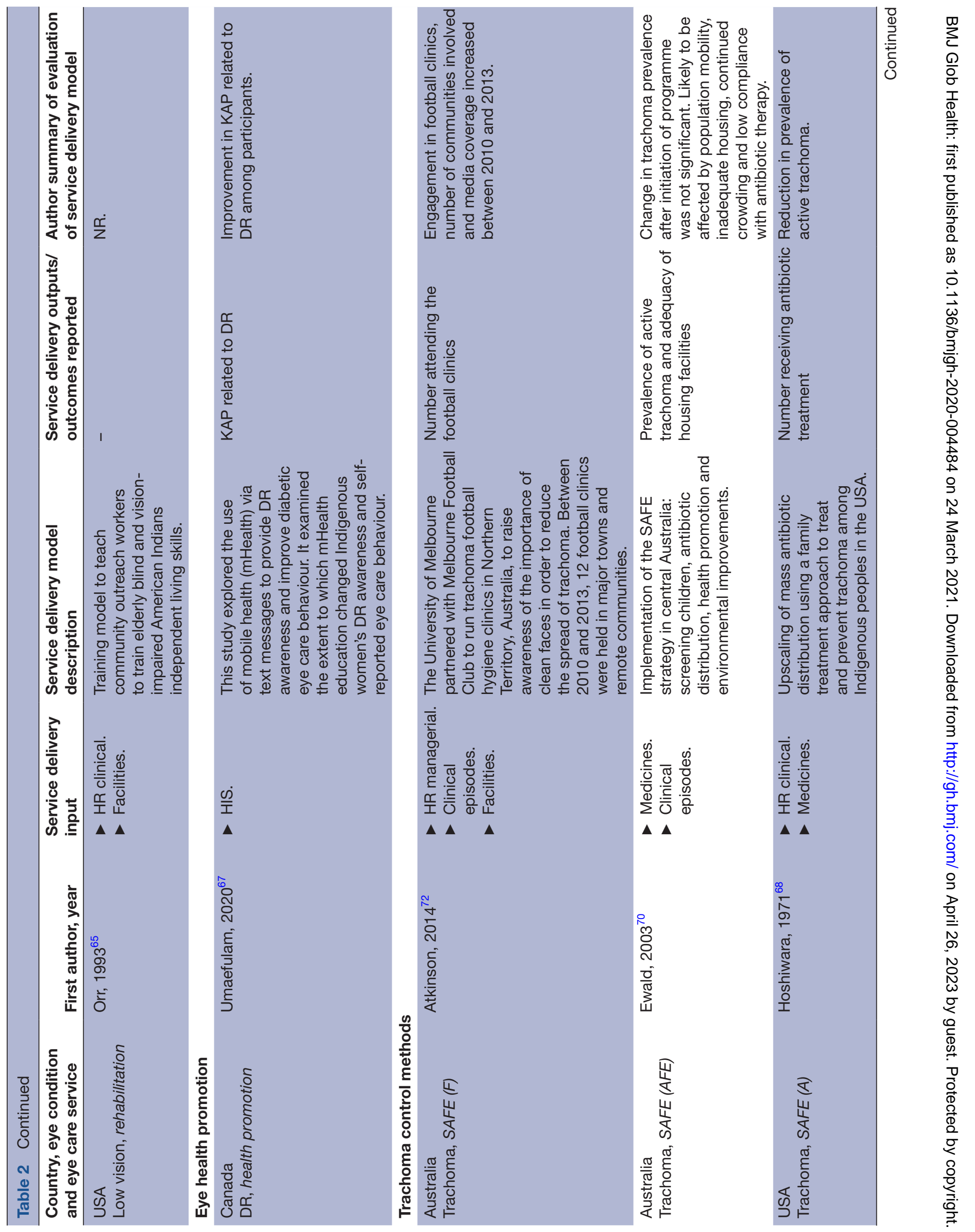




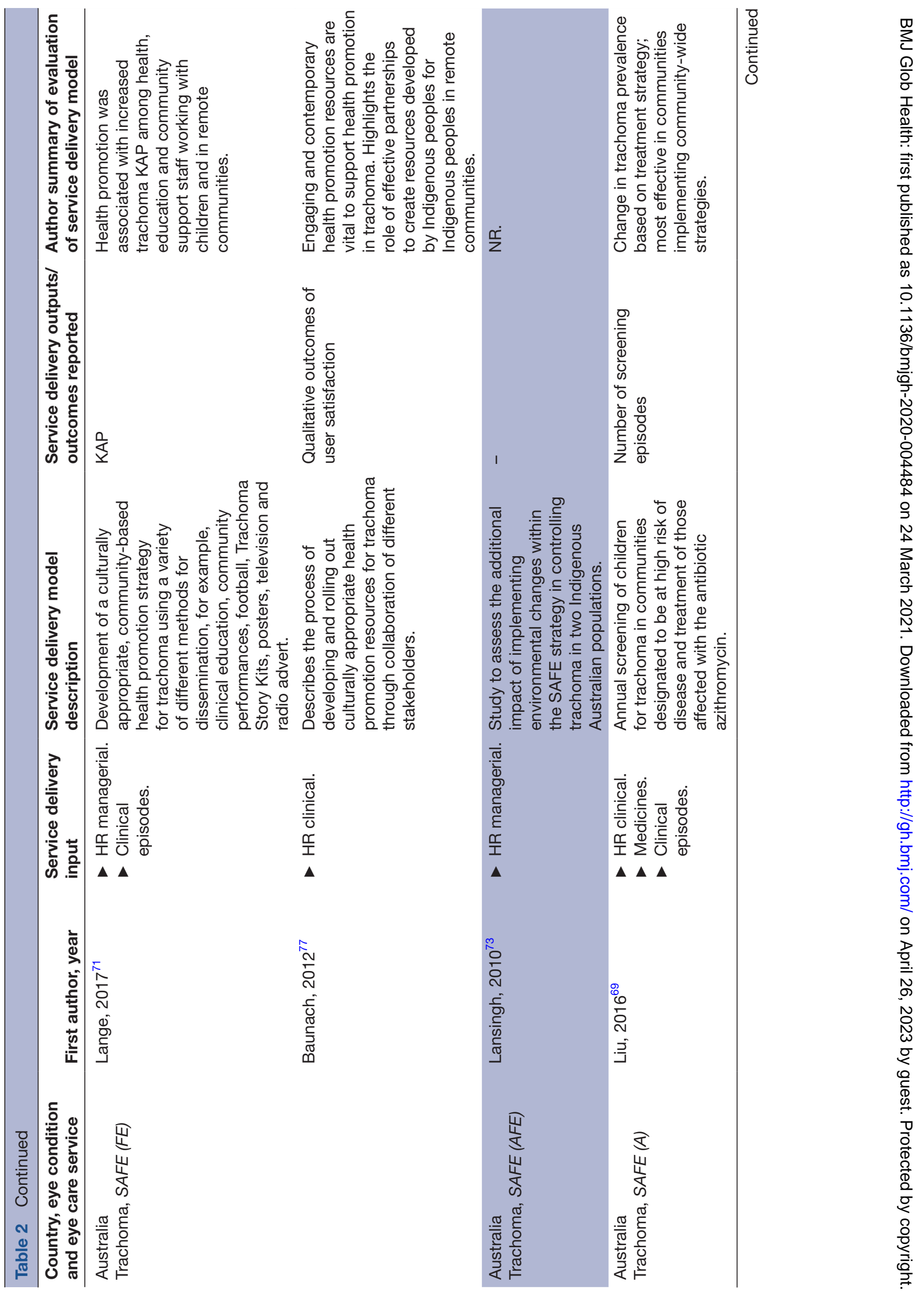




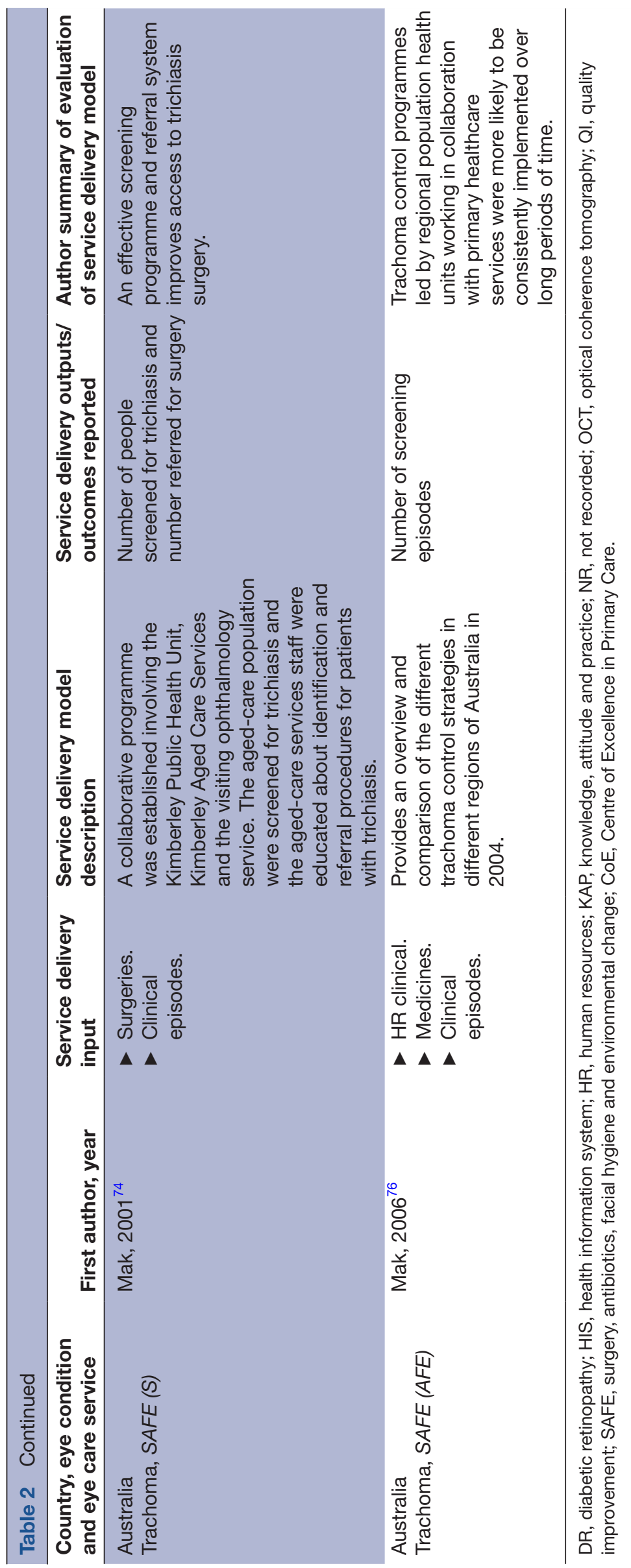


Two models described the use of training Indigenous health workers to deliver community eye care services: one trained community outreach workers to teach visionimpaired older people independent living skills in the $\mathrm{USA}^{65}$ and the other trained Aboriginal health workers in primary eye care in Australia. ${ }^{66}$ One model described the use of mobile phones (mobile health) to carry out eye health promotion regarding diabetic retinopathy with Indigenous women in Canada. ${ }^{67}$

Lastly, eight models focused exclusively on access to trachoma control measures in the USA $(n=1)^{68}$ and Australia $(n=7) .{ }^{69-77}$ Trachoma requires specific, welldefined interventions which are not widely applicable to other eye conditions: SAFE (s urgery for trichiasis, mass antibiotic distribution, promotion of facial hygiene and environmental change). One model focused specifically on screening for trichiasis, ${ }^{74}$ two models described mass antibiotic distribution, ${ }^{6869}$ and three others focused on all aspects of trachoma except trichiasis surgery. ${ }^{70} 7376$ One model described a health promotion strategy to increase facial hygiene practices using clinics at football matches, ${ }^{72}$ and another described a multicomponent health promotion strategy for trachoma implemented in Northern Territory, Australia. ${ }^{71} 77$

\section{Effectiveness of implemented service delivery models \\ Reported outcomes and evaluations}

Of the 50 studies reporting an implemented model, 41 $(82 \%)$ reported at least one outcome related to access (table 2). These studies also provided some reflection on whether the eye care service delivery model was successful, but this tended to draw on changes in service outputs, such as consultations or spectacle dispensing, without any statistical or comparative analysis. No studies evaluated the long-term impact, for example, change in the burden of vision impairment, among an Indigenous population as a result of implementing a service delivery model (table 2).

\section{Indigenous engagement}

Authors included an explicit statement that the model was designed to be socially and/or culturally appropriate in $20(40 \%)$ implemented service delivery model studies. Strategies included employing regional eye health coordinators from within the Indigenous community to improve coordination between healthcare providers and the community ${ }^{496}$ and using Indigenous health workers to carry out community eye care that is culturally sensitive. ${ }^{35} 43$ A study in Canada demonstrated that a culturally sensitive, community-based teleophthalmology clinic for Aboriginal Canadians significantly increased attendance rates, ${ }^{34}$ while attendees of a community-based diabetic retinopathy screening within an Indigenous health service in metropolitan Australia reported the screening experience was more 'culturally safe' ${ }^{38}$ One example of a culturally sensitive trachoma programme was the multicomponent health promotion model implemented in Northern Territory, Australia. Several different health promotion initiatives were centred around the 'Trachoma Story Kit', developed as a culturally appropriate health promotion material with input from Aboriginal health services, Departments of Health and Education, nongovernmental organisations, community programmes and environmental health. The implementation of the programme was advised throughout on cultural safety and acceptability by the Ngumbin Reference Group of Elders and Aboriginal health workers. ${ }^{71} 77$

Authors reported that Indigenous peoples were involved in the design of the eye care service in 17 of the 50 studies $(34 \%)$. For example, when establishing a spectacle subsidy scheme in Victoria, Australia, the leaders of the target community were included as stakeholders, community elders were involved in the selection of spectacle frames, and an Indigenous patient pathway coordinator was selected from the community. ${ }^{52}$ In a teleophthalmology screening programme in Canada health providers sent letters to community leaders to assess interest in the scheme, invited community members to attend project launch meetings and organised clinic dates and times based on preferences of the community. ${ }^{43}$ Other studies described how Indigenous community members and/or leaders were consulted to help design eye care services. For example, in a cataract surgical service redesign programme in Australia, community members from the target Indigenous population were involved in brainstorming the service redesign. ${ }^{57}$ In Canada ideas for making a screening programme more culturally acceptable were gained from consulting a spiritual liaison from the Indigenous community. ${ }^{34}$

\section{Access dimensions}

Only 2 of the 46 implemented service delivery models described a model that addressed all stages of access outlined in the Levesque $e t a l^{24}$ access framework; these and other models are mapped against Levesque $e t$ al $\mathrm{s}$ framework in figure 2. The first model addressing all access stages involved teleophthalmology screening for First Nations clients with diabetes in Canada. ${ }^{43}$ This programme distributed health promotion material before the launch of the programme, eliminated travels costs and time for the client by bringing the clinic to the community, provided screening free of charge, and aimed to engage the community through supporting young people from the targeted community to gain work experience within the scheme. Second, a low-cost spectacle scheme implemented in Victoria, Australia increased transparency through use of members of Indigenous community as stakeholders. They improved accessibility by increasing the number of service sites, clinical sessions, optometrists and expanded to more rural locations. The spectacles were provided at a reduced fixed cost, services were provided within the existing culturally appropriate Aboriginal health service facilities, and community engagement was undertaken to plan and implement the scheme. ${ }^{78}$ 


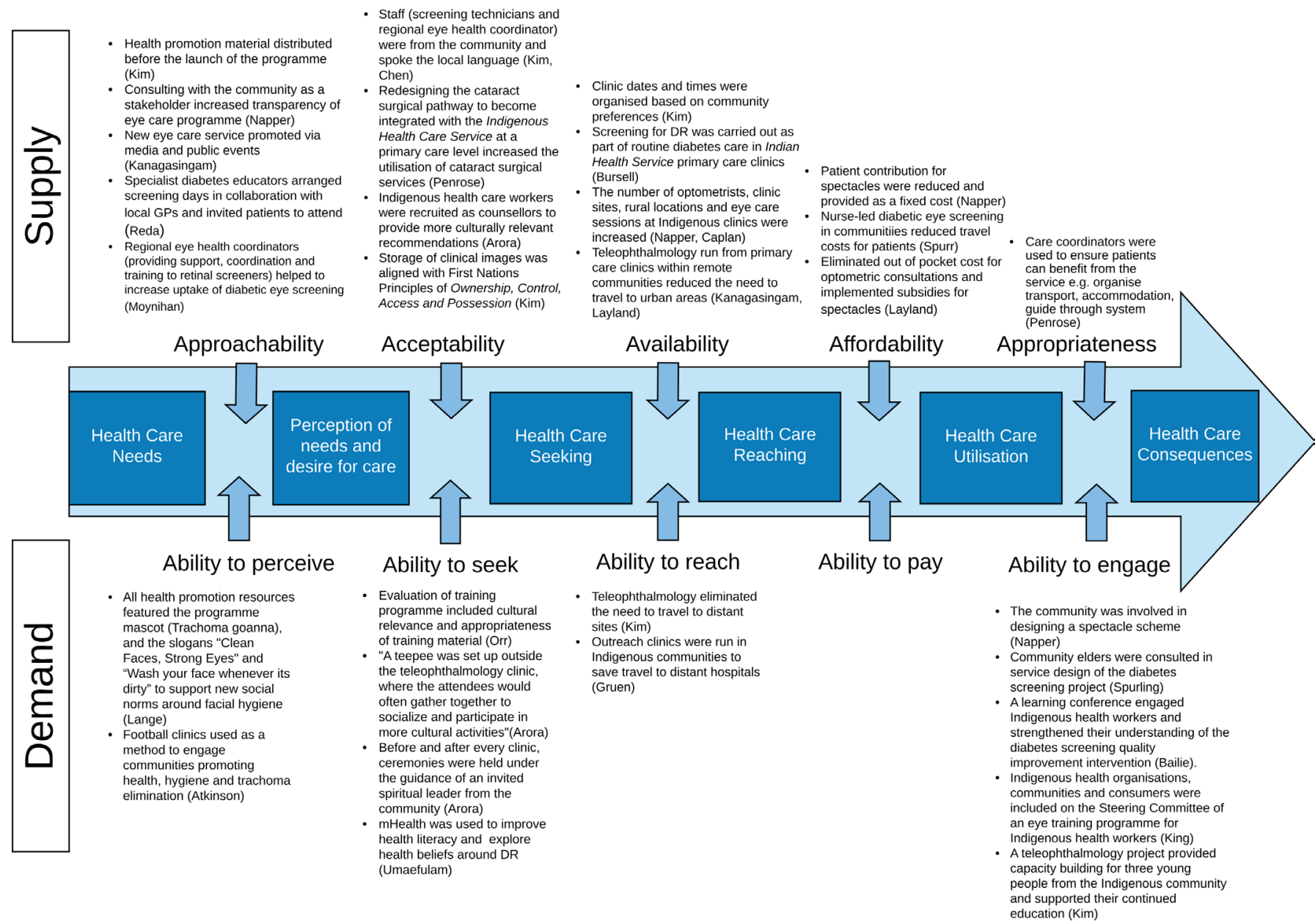

Figure 2 Components of identified service delivery models to improve access to eye care for Indigenous peoples, mapped against the stages of the Levesque et $a^{24}$ framework (illustrative examples extracted from 50 implemented model studies). DR, diabetic retinopathy; GP, general practitioner; mHealth, mobile health.

Across all studies, 'availability/ability to reach' was the access stage most often addressed, with 44 studies reporting some aspect of increasing availability of eye services for Indigenous peoples. This commonly involved increasing the number of clinical sites, ${ }^{5152}$ providing services in more remote/rural areas, ${ }^{43}{ }^{61}$ expanding human resources ${ }^{51} 52$ or providing more flexible clinic operating times. ${ }^{43}$ Other access stages were described by far fewer studies, for example, 'appropriateness/ability to engage' $(n=17)$. Examples exclusively focused on improving the ability of the community to engage in the eye care service design and implementation..$^{82} 5466$ 'Acceptability/ability to seek' was addressed in 18 studies; examples included employing a community eye health coordinator, ${ }^{36} 495760$ recruiting health workers from the targeted Indigenous community ${ }^{34} 4360$ and liaising with existing Indigenous healthcare systems. ${ }^{39}{ }^{45} 5761$ In terms of 'approachability/ability to perceive' $(n=18)$, the literature provides some positive examples of increasing community awareness of eye care services to improve approachability, ${ }^{36} 37434552$ but there were fewer examples of attempts to improve a community's 'ability to perceive'. ${ }^{71} 72$ 'Affordability/ability' to pay was rarely reported $(n=7)$. There were no examples of improving 'ability to pay', but some delivery models described fixed, low-cost or free eye care services. ${ }^{5253}$ Across all five access dimensions, models on the supply side were more commonly described than the demand side.

\section{Non-implemented models}

An additional 17 reports were identified that discussed wider aspects of service delivery and access to eye care for Indigenous peoples in high-income countries, but did not specifically describe or evaluate an implemented service delivery model. Key strategies for improving access to eye care were drawn from these reports and are summarised in table 3. These strategies have been matched with the five service delivery models described in the 'Implemented service delivery models' section, and an additional category of broader themes has also been included.

\section{DISCUSSION}

\section{Summary of evidence}

What were the numbers and characteristics of published reports describing service delivery models to improve access to eye care for Indigenous populations in high-income countries?

Most studies identified in this review described eye care delivery models to improve access to eye care for Indigenous 
Table 3 Strategies for improving access to eye care for Indigenous peoples proposed in reports of non-implemented models $(n=17)$

\begin{tabular}{|c|c|}
\hline Service delivery model & Proposed strategies to improve access \\
\hline Teleophthalmology screening & $\begin{array}{l}\text { Ensure culturally appropriate 'patient-provider' communication regarding diabetic } \\
\text { retinopathy to reduce non-adherence to screening programmes. }\end{array}$ \\
\hline $\begin{array}{l}\text { Eye care integrated within } \\
\text { primary care and Indigenous } \\
\text { healthcare }\end{array}$ & $\begin{array}{l}\text { Train primary care staff to enable primary care to support eye care delivery. }{ }^{62} 8187-90 \\
\text { Design tertiary ophthalmic services to incorporate needs of Indigenous peoples to improve } \\
\text { uptake. } 7288 \\
\text { Ensure primary healthcare staff have knowledge of a well-defined patient pathway from } \\
\text { community identification of eye care need to referral, treatment and monitoring. }{ }^{91}\end{array}$ \\
\hline $\begin{array}{l}\text { Outreach ophthalmology and } \\
\text { optometry }\end{array}$ & $\begin{array}{l}\text { Improve coordination between Indigenous healthcare system and eye care } \\
\text { services. }\end{array}$ \\
\hline $\begin{array}{l}\text { Education, training and } \\
\text { health promotion }\end{array}$ & $\begin{array}{l}\text { Provide culturally appropriate eye health knowledge training for healthcare workers and their } \\
\text { communities. }{ }^{709095}\end{array}$ \\
\hline Trachoma control measures & $\begin{array}{l}\text { Optimise the intensity and strategy of comprehensive interventions in Australian Aboriginal } \\
\text { communities with endemic trachoma. }\end{array}$ \\
\hline $\begin{array}{l}\text { Broader service delivery } \\
\text { components }\end{array}$ & $\begin{array}{l}\text { Use a health systems approach when designing eye care services. }{ }^{90} \\
\text { Calculate estimates of cost, cost-effectiveness and models of funding eye care. }{ }^{889099100} \\
\text { Deliver culturally appropriate eye care services to reduce barriers to patient access. }{ }^{118889101} \\
\text { Distribute eye care professionals and funding equitably. }{ }^{136289} \\
\text { Plan sustainable eye care services. }{ }^{101} \\
\text { Ensure monitoring and evaluation to collect, analyse and report local, regional and national } \\
\text { data on eye care services, quality and satisfaction. }{ }^{89} 90\end{array}$ \\
\hline
\end{tabular}

peoples in Australia and focused on the delivery of diabetic eye care services or trachoma elimination strategies. There was very little literature from other high-income countries with Indigenous peoples such as New Zealand, Canada, USA, Taiwan and Greenland, and none from countries such as Singapore, Uruguay and Chile. ${ }^{9}$ This lack of evidence is despite documented inequality in the prevalence of ocular conditions among Indigenous populations in many of these countries. In their recent systematic review, Foreman et at identified the leading causes of vision impairment (visual acuity worse than 6/18) among Indigenous adults worldwide were uncorrected refractive error (responsible for an estimated $54.0 \%-65.1 \%$ of vision impairment) and cataract $(20.1 \%-29.3 \%)$. The relative magnitude of these two conditions is not reflected in the studies we identified; only four studies specifically focused on the delivery of optometry and/or refraction services to Indigenous peoples, ${ }^{51527980}$ while a further four focused on cataract services $^{50576181}$ (table 1).

What methods and interventions are used by the identified service delivery models to improve access to eye care for Indigenous populations?

There was consistency among the studies in the service delivery models described. The most commonly described model was teleophthalmology, specifically the integration of teleophthalmology screening into existing primary care and/or Indigenous healthcare services. This model is in line with recommendations outlined in Australia's Roadmap to Close the Gap for Vision ${ }^{82}$ and aims to improve the identification and referral of eye care needs from the primary care setting. The use of outreach services to
Indigenous peoples was described less frequently in the literature.

Fewer than half of the studies reporting implemented models discussed methods to make eye care service delivery socially and culturally acceptable to the Indigenous peoples being targeted, and even fewer reported involving Indigenous peoples in the design and implementation of services. This contrasts with the message repeatedly drawn from the non-implemented model studies that services need to be culturally appropriate in order to overcome the documented barriers to access to eye care among Indigenous peoples. Clearly there is a gap between what is discussed as a theoretical 'gold standard' approach to providing eye care to Indigenous peoples and what is carried out in practice. Some studies in this review provided examples of how this can be achieved, such as the Canadian teleophthalmology screening service that placed a teepee outside the clinic for patients to participate in cultural activities such as bracelet making and sharing of food, and to enable patients to discuss their physical, mental, spiritual and emotional health as part of their eye healthcare. ${ }^{34}$

Most of the models we identified in the literature (eg, teleophthalmology, integration into Indigenous primary health, outreach, training Indigenous health workers) aimed to keep eye care within Indigenous communities. Despite this, very few studies referred to cultural responsiveness, cultural safety or engagement. If health service interventions are brought into communities, but are not engaged with communities, eye health outcomes are more likely to remain the same. Service delivery 
models need to adopt frameworks that place cultural responsiveness at their core. For example, a framework to provide culturally responsive service delivery to Indigenous peoples has been developed by the Indigenous Allied Health Australia. ${ }^{83}$ The cultural responsiveness framework provides practical strategies to enable health services to provide culturally safe and responsive services that meet the needs of Indigenous peoples, with continued dialogue and engagement with Indigenous peoples placed at the core of the framework.

The literature identified tended to describe supply-side, rather than demand-side strategies, including methods to improve availability such as scheduling clinical services more frequently and having services located in isolated communities. Few studies described ways in which the arguably more challenging components of service delivery (appropriateness/ability to engage, acceptability/ability to seek and approachability/ability to perceive) could be improved. These demand-side access dimensions (ability to engage, seek and perceive) have been discussed in the wider literature as important areas to target to improve access to eye care. A recent qualitative study of determinants of eye health among Indigenous Australians with diabetes found that trust, culture and communication were three key areas in need of improvement in order to improve patient access to eye services and eye health outcomes. ${ }^{11}$ In particular, this study found that a lack of Indigenous language interpreters, lack of cultural literacy for non-indigenous clinicians and distrust of clinicians and health services contribute to reduced access to and uptake of eye care services. One proposal is the introduction of Indigenous liaison officers to increase cultural safety and trust in hospital settings and provide advocacy and non-clinical support. These non-clinical roles could supplement the role of eye health coordinators which have been commonly mentioned in the literature in this review. In addition, cultural responsiveness training for non-Indigenous clinical staff is a further tool that can be used to enable culturally safe access to eye care services.

Very few studies discussed affordability, despite cost often being stated as a barrier to accessing eye care. ${ }^{84}$ The preponderance of reports from Australia may explain this, given that government funding is available for eye care examinations by ophthalmologists and optometrists. The review demonstrated a lack of rigorous evaluation of service delivery with regard to access dimension outcomes. No study provided a comprehensive evaluation of outcomes, such as the change in the burden of vision impairment within the population where the eye care service was delivered. Instead, many studies reported on project outputs, such as change in patient attendance numbers.

What are the current gaps in the literature and what lessons can be learnt regarding models that have been successful in improving access?

Promisingly, most studies were published after 2010, suggesting that the published literature on this topic is increasing over time. However, while the volume is increasing, the scope remains narrow. The geographical spread needs to increase, in particular with more research outside Australia, and the inclusion of other high-income countries with marginalised Indigenous peoples, for which no literature was identified in this review. Many of the service delivery components, particularly those outlined in the non-implemented model reports, are applicable to most nations and should not be limited to one country or region. However, it is important that implementation research is conducted in the setting within which the service is needed and ensures local community engagement and ownership. ${ }^{6}$

The review also identified a limited clinical scope. We recommend further research beyond the current focus on diabetic retinopathy screening. This service requires specialist photography equipment, health information systems and technologies which are not always applicable to other aspects of eye care, and therefore findings from these studies lack generalisability to other eye care services. The review revealed a major gap in reporting the short-term and long-term clinical outcomes of eye care services developed for Indigenous peoples in highincome countries. Outputs (numbers attending, satisfaction surveys) were more commonly reported in the literature. Without more comprehensive evaluations of services, the success of delivery models remains largely unknown.

Lastly, the methodological approaches used could be strengthened to provide more robust evidence for interventions that are effective. Although this review, as a scoping review, did not formally assess the quality of included studies, we were able to identify a lack of fully evaluated long-term implementation studies to robustly assess a service delivery model for eye care in this setting. Although service delivery outcomes were collected for most studies, few studies evaluated the model using all five access dimensions and none was able to show the long-term impact of the intervention.

\section{Limitations}

There are some differences between our published protocol ${ }^{23}$ and this scoping review. First, there were a larger number of studies identified in the literature search than we had predicted. We therefore decided not to include grey literature as we felt the published literature alone would answer our research questions and we were limited by time and resources to additionally search all grey literature on this topic. We are aware that this scoping review includes only models that have been published in the peer-reviewed literature and therefore may not reflect all service delivery models in use. Second, in the protocol we stated we would collect information on the 'enabling health system functions' described in the model. As we started the iterative process for data charting it became clear that these data items were rare within the reports and better captured by other items we collected and analysed, such as the description of the 
intervention. Third, the literature was very heterogeneous, and in attempting to keep the scope very broad we had to analyse reports in different ways, as some did not describe implemented service delivery models. Although we could not extract from these reports the data items we had proposed to extract in our protocol, we decided to retain 'non-implemented model reports' as they provided information on wide-reaching themes around the subject, which have helped to deepen our understanding. As we were completing our review, the CONSIDER (Consolidated criteria for strengthening reporting of health research involving indigenous peoples) statement was published providing guidelines for strengthening the reporting of health research involving Indigenous peoples. ${ }^{85}$ Our team includes Indigenous researchers and people who have worked in Indigenous primary healthcare and Indigenous eye care. However, we recognise that our review falls short of the CONSIDER statement in several areas, and in particular could have been further strengthened had we engaged Indigenous peoples with vision impairment. Lastly, as the majority of Indigenous peoples live in low-income and middle-income countries, by focusing only on high-income countries in this review it is likely we will have missed an important proportion of eye care services among Indigenous peoples living elsewhere. This will provide an important next research priority.

\section{CONCLUSIONS}

This scoping review identified a narrow geographical and clinical focus within the published literature on service delivery models to improve access to eye care for Indigenous peoples within high-income countries. The geographical locations, eye diseases targeted and eye care services delivered do not reflect the epidemiology of eye disease among Indigenous peoples in high-income countries. In 2015, the UNPFII called for culturally, linguistically and geographically appropriate models of care for Indigenous peoples, as well as participation by Indigenous peoples in the design and implementation of health policies and programmes. ${ }^{6}$ Disappointingly this review has found few examples of this approach in published studies. There are isolated examples of improvements in access to eye care when services are developed in partnership with Indigenous peoples. However, to realise the SDGs and leave no one behind, much more must be done to ensure Indigenous peoples can access eye care.

Twitter Helen Burn @burn_hburn

Contributors $\mathrm{HB}, \mathrm{JR}, \mathrm{LH}, \mathrm{JB}, \mathrm{AB}, \mathrm{MH}, \mathrm{JRE}$ were involved in designing the research protocol. $\mathrm{HB}, \mathrm{JR}, \mathrm{LH}, \mathrm{JB}, \mathrm{AB}, \mathrm{MH}$ carried out the data collection. $\mathrm{HB}$ drafted the paper. HB, JR, LH, JB, AB, MH, JRE, MJB assisted in writing the paper.

Funding This work was supported by The University of Auckland Faculty Research Development Fund (grant number 3716758). The Lancet Global Health Commission on Global Eye Health is supported by The Queen Elizabeth Diamond Jubilee Trust, Moorfields Eye Charity (grant number GR001061), NIHR Moorfields Biomedical Research Centre, Wellcome Trust, Sightsavers, The Fred Hollows Foundation, SEVA Foundation, British Council for the Prevention of Blindness and Christoffel Blind Mission. MJB is supported by the Wellcome Trust (207472/Z/17/Z). JR's position at
The University of Auckland is funded by the Buchanan Charitable Foundation, New Zealand.

Competing interests None declared.

Patient consent for publication Not required.

Provenance and peer review Not commissioned; externally peer reviewed.

Data availability statement Data sharing not applicable as no datasets generated and/or analysed for this study. No participant data were used in this scoping review.

Supplemental material This content has been supplied by the author(s). It has not been vetted by BMJ Publishing Group Limited (BMJ) and may not have been peer-reviewed. Any opinions or recommendations discussed are solely those of the author(s) and are not endorsed by BMJ. BMJ disclaims all liability and responsibility arising from any reliance placed on the content. Where the content includes any translated material, BMJ does not warrant the accuracy and reliability of the translations (including but not limited to local regulations, clinical guidelines, terminology, drug names and drug dosages), and is not responsible for any error and/or omissions arising from translation and adaptation or otherwise.

Open access This is an open access article distributed in accordance with the Creative Commons Attribution 4.0 Unported (CC BY 4.0) license, which permits others to copy, redistribute, remix, transform and build upon this work for any purpose, provided the original work is properly cited, a link to the licence is given, and indication of whether changes were made. See: https://creativecommons.org/ licenses/by/4.0/.

\section{ORCID iDs}

Helen Burn http://orcid.org/0000-0002-1469-8169

Lisa Hamm http://orcid.org/0000-0003-2777-7146

Joanna Black http://orcid.org/0000-0002-5100-8796

Anthea Burnett http://orcid.org/0000-0003-3772-6625

Matire Harwood http://orcid.org/0000-0003-1240-5139

Matthew J Burton http://orcid.org/0000-0003-1872-9169

Jennifer R Evans http://orcid.org/0000-0002-6137-2030

Jacqueline Ramke http://orcid.org/0000-0002-5764-1306

\section{REFERENCES}

1 UN General Assembly. United Nations Declaration on the rights of Indigenous peoples: resolution / adopted by the General Assembly, 2 October 2007, A/RES/61/295, 2007. Available: https://www. refworld.org/docid/471355a82.html [Accessed 24 Feb 2021].

2 UN General Assembly. Transforming our world : the 2030 Agenda for Sustainable Development, 21 October 2015, A/RES/70/1, 2015. Available: https://www.refworld.org/docid/57b6e3e44.html [Accessed $24 \mathrm{Feb}$ 2021].

3 Hall G, Patrinos H. Indigenous peoples, poverty and development. New York: Cambridge University Press, 2012.

4 United Nations Department for Economic and Social Affairs. Secretariat of the Permanent Forum on Indigenous Issues. State of the world's indigenous peoples 2009.

5 Anderson I, Robson B, Connolly M, et al. Indigenous and tribal peoples' health (the Lancet-Lowitja Institute global collaboration): a population study. Lancet 2016;388:131-57.

6 United Nations Permanent Forum on Indigenous Issues. State of the World's indigenous peoples: indigenous peoples' access to health services; 2nd volume, 2015. Available: https://www.un.org/ development/desa/indigenouspeoples/publications/2015/09/stateof-the-worlds-indigenous-peoples-2nd-volume-health/

7 Wylie L, McConkey S. Insiders' Insight: Discrimination against Indigenous Peoples through the Eyes of Health Care Professionals. $J$ Racial Ethn Health Disparities 2019;6:37-45.

8 Australian Institute of Health and Welfare 2018. Australia's health 2018. Cat. No. AUS 221. Canberra: AlHW, 2018. doi:10.25816/5ec1e56f25480

9 Foreman J, Keel S, van Wijngaarden P, et al. Prevalence and causes of visual loss among the Indigenous peoples of the world: a systematic review. JAMA Ophthalmol 2018;136:567-80.

10 Foreman J, Xie J, Keel S, et al. The prevalence and causes of vision loss in Indigenous and non-Indigenous Australians: the National eye health survey. Ophthalmology 2017;124:1743-52.

11 Yashadhana A, Fields T, Blitner G, et al. Trust, culture and communication: determinants of eye health and care among Indigenous people with diabetes in Australia. BMJ Glob Health 2020;5:1-9. 
12 Foreman J, Xie J, Keel S, et al. Utilization of eye health-care services in Australia: the National eye health survey. Clin Exp Ophthalmol 2018;46:213-21.

13 Kelaher M, Ferdinand A, Taylor $\mathrm{H}$. Access to eye health services among Indigenous Australians: an area level analysis. BMC Ophthalmol 2012;12:51.

14 Lee ET, Russell D, Morris T, et al. Visual impairment and eye abnormalities in Oklahoma Indians. Arch Ophthalmol 2005;123:1699-704.

15 Mansberger SL, Romero FC, Smith NH, et al. Causes of visual impairment and common eye problems in northwest American Indians and Alaska natives. Am J Public Health 2005;95:881-6.

16 Ross SA, McKenna A, Mozejko S. Diabetic retinopathy in native and non native Canadians. Chakrabarti S, editor. Exp Diabetes Res 2007;2007:76271.

17 Simmons D, Clover G, Hope C. Ethnic differences in diabetic retinopathy. Diabet Med 2007;24:1093-8.

18 Ramke J, Jordan V, Vincent AL, et al. Diabetic eye disease and screening attendance by ethnicity in New Zealand: a systematic review. Clin Exp Ophthalmol 2019;47:937-47.

19 Newlands SJ, Hoy BM, Wilson GA. Cataract surgery in Hauora Tairāwhiti and need for improving access for Māori. Clin Exp Ophthalmol 2019;47:145-7.

20 Campbell R, Sutherland R, Khan S. First nations people with diabetes in Ontario: methods for a longitudinal population-based cohort study. C Open 2019;7:E680-8.

21 Jones R, Crowshoe L, Reid P, et al. Educating for Indigenous health equity: an international consensus statement. Acad Med 2019;94:512-9.

22 Burton MJ, Ramke J, Marques AP, et al. The Lancet global health Commission on global eye health: vision beyond 2020. Lancet Glob Health 2021;7. doi:10.1016/S2214-109X(20)30488-5. [Epub ahead of print: 16 Feb 2021].

23 Burn H, Black J, Harwood M, et al. Eye care delivery models to improve access to eye care for Indigenous people in highincome countries: protocol for a scoping review. BMJ Open 2019;9:e029214.

24 Levesque J-F, Harris MF, Russell G. Patient-Centred access to health care: conceptualising access at the interface of health systems and populations. Int J Equity Health 2013;12:18-1.

25 Tricco AC, Lillie E, Zarin W, et al. PRISMA extension for scoping reviews (PRISMA-ScR): checklist and explanation. Ann Intern Med 2018;169:467.

26 The World Bank. Nepal | data, 2018. Available: https://data. worldbank.org/country/nepal

27 Bowyer NK. A primary care team approach to the prevention of ocular complications of diabetes: a program review. J Am Optom Assoc 1997;68:233-42.

28 Spurr S, Bullin C, Bally J, et al. Nurse-Led diabetic retinopathy screening: a pilot study to evaluate a new approach to vision care for Canadian Aboriginal peoples. Int J Circumpolar Health 2018;77:1422670.

29 Barry CJ, Constable IJ, McAllister IL, et al. Diabetic screening in Western Australia: a photographer's perspective. $J$ Vis Commun Med 2006;29:66-75.

30 Brazionis L, Jenkins A, Keech A, et al. Diabetic retinopathy in a remote Indigenous primary healthcare population: a central Australian diabetic retinopathy screening study in the telehealth eye and associated medical services network project. Diabet Med 2018;35:630-9.

31 Villalba C, Askew D, Jaiprakash A, et al. A mixed-methods retrospective study: 10 years of diabetic retinopathy screening in urban Aboriginal and Torres Strait Islander primary care. Aust J Prim Health 2019;25:24-30.

32 Pedersen ML. Diabetes care in the dispersed population of Greenland. A new model based on continued monitoring, analysis and adjustment of initiatives taken. Int $J$ Circumpolar Health 2019;78:1709257.

33 Fonda SJ, Bursell S-E, Lewis DG, et al. The Indian health service primary care-based Teleophthalmology program for diabetic eye disease surveillance and management. Telemed J E Health 2020;26:1466-1474.

34 Arora S, Kurji AK, Tennant MTS. Dismantling sociocultural barriers to eye care with tele-ophthalmology: lessons from an Alberta Cree community. Clin Invest Med 2013;36:57-63.

35 Murray RB, Metcalf SM, Lewis PM, et al. Sustaining remote-area programs: retinal camera use by Aboriginal health workers and nurses in a Kimberley partnership. Med J Aust 2005;182:520-3.

36 Moynihan V, Turner A. Coordination of diabetic retinopathy screening in the Kimberley region of Western Australia. Aust J Rural Health 2017:25:110-5.
37 Kanagasingam Y, Boyle J, Vignarajan J, et al. Establishing an Indigenous tele-eye care service. Annu Int Conf IEEE Eng Med Biol Soc 2015;2015:1608-11.

38 Spurling GKP, Askew DA, Hayman NE, et al. Retinal photography for diabetic retinopathy screening in Indigenous primary health care: the Inala experience. Aust N Z J Public Health 2010;34 Suppl 1:S30-3.

39 Bursell S-E, Fonda SJ, Lewis DG, et al. Prevalence of diabetic retinopathy and diabetic macular edema in a primary care-based teleophthalmology program for American Indians and Alaskan natives. PLoS One 2018;13:e0198551.

40 Carroll M, Cullen T, Ferguson S, et al. Innovation in Indian healthcare: using health information technology to achieve health equity for American Indian and Alaska native populations. Perspect Health Inf Manag 2011;8:1d.

41 Mansberger SL, Gleitsmann K, Gardiner S, et al. Comparing the effectiveness of telemedicine and traditional surveillance in providing diabetic retinopathy screening examinations: a randomized controlled trial. Telemed J E Health 2013;19:942-8.

42 Karagiannis A, Newland H. Mobile retinal photography. A means of screening for diabetic retinopathy in Aboriginal communities. Aust N Z J Ophthalmol 1996;24:333-7.

$43 \mathrm{Kim}$ J, Driver DD. Teleophthalmology for first nations clients at risk of diabetic retinopathy: a mixed methods evaluation. JMIR Med Inform 2015;3:e10.

44 Jin AJ, Martin D, Maberley D, et al. Evaluation of a mobile diabetes care telemedicine clinic serving Aboriginal communities in northern British Columbia, Canada. Int J Circumpolar Health 2004;63 Suppl 2:124-8.

45 Reda E, Dunn P, Straker C, et al. Screening for diabetic retinopathy using the mobile retinal camera: the Waikato experience. $N Z$ Med J 2003;116:U562

46 Jagadish P, Dalziel D. Discharge outcomes of patients referred to specialist eye clinic from diabetic retinopathy screening in Northland (2014-15). N Z Med J 2017;130:89-93.

47 O'Halloran RA, Turner AW. Evaluating the impact of optical coherence tomography in diabetic retinopathy screening for an Aboriginal population. Clin Exp Ophthalmol 2018;46:116-21.

48 McConnell EA, Newland HS, Manning J, et al. Technology assessment applied: a comparison of ophthalmic diagnostic techniques to detect diabetic retinopathy among Aboriginal people in central Australia. Contemp Nurse 1993;2:23-8.

49 Elliott G, Smith AC, Bensink ME, et al. The feasibility of a community-based mobile telehealth screening service for Aboriginal and Torres Strait Islander children in Australia. Telemedicine and e-Health 2010;16:950-6.

50 McGlacken-Byrne A, Turner AW, Drinkwater J. Review of cataract surgery in rural North Western Australia with the lions outback vision. Clin Exp Ophthalmol 2019;47:802-3.

51 Caplan L. The American Indian--the long road to eye care. J Am Optom Assoc 1978;49:203-5.

52 Napper G, Fricke T, Anjou MD, et al. Breaking down barriers to eye care for Indigenous people: a new scheme for delivery of eye care in Victoria. Clin Exp Optom 2015;98:430-4.

53 Layland B, Holden B, Evans K, et al. ICEE/AHMRC NSW Aboriginal eye and Visioncare program, Australia. Rural Remote Health 2004;4:247.

54 Bailie R, Si D, Dowden M, et al. Improving organisational systems for diabetes care in Australian Indigenous communities. BMC Health Serv Res 2007;7:67.

55 McDermott RA, Schmidt BA, Sinha A, et al. Improving diabetes care in the primary healthcare setting: a randomised cluster trial in remote Indigenous communities. Med J Aust 2001;174:497-502.

56 Hayward MN, Pace R, Zaran $\mathrm{H}$, et al. Closing the Indigenous health gap in Canada: results from the transformation of Indigenous primary healthcare delivery (forge ahead) program. Diabetes Res Clin Pract 2020;162:108066.

57 Penrose L, Roe Y, Johnson NA, et al. Process redesign of a surgical pathway improves access to cataract surgery for Aboriginal and Torres Strait Islander people in South East Queensland. Aust J Prim Health 2018;24:135-40.

58 Jatkar U, Anjou MD, Taylor HR. Grampians - closing the Gap in Indigenous eye health. Med J Aust 2017;206:97.

59 Yashadhana A, Morse A, Tatipata S, et al. Using quality improvement strategies to strengthen regional systems for Aboriginal and Torres Strait Islander eye health in the Northern Territory. Aust J Rural Health 2020;28:60-6.

60 Chen N, Hsieh H-P, Tsai R-K, et al. Eye care services for the populations of remote districts in eastern Taiwan: a practical framework using a mobile vision van unit. Rural Remote Health 2015;15:3442. 
61 Gruen RL, Bailie RS, Wang Z, et al. Specialist outreach to isolated and disadvantaged communities: a population-based study. Lancet 2006;368:130-8.

62 Turner AW, Mulholland WJ, Taylor HR. Coordination of outreach eye services in remote Australia. Clin Exp Ophthalmol 2011;39:344-9.

63 Maher L, Brown AM, Torvaldsen S, et al. Eye health services for Aboriginal people in the Western region of NSW, 2010. N S W Public Health Bull 2012;23:81-6.

64 Robin AL, Arkell S, Gilbert SM, et al. Q-Switched neodymium-YAG laser iridotomy. A field trial with a portable laser system. Arch Ophthalmol 1986;104:526-30.

65 Orr AL. Training outreach workers to serve American Indian elders with visual impairment and diabetes. J Vis Impair Blind 1993;87:336-40.

66 King M, Baxter S. Co-Operative inquiry: the development of a visual impairment prevention program initiative for two Aboriginal communities in South Australia. Contemp Nurse 2003;15:241-8.

67 Umaefulam V, Premkumar K. Impact of mobile health in diabetic retinopathy awareness and eye care behavior among Indigenous women. Mhealth 2020;6:14.

68 Hoshiwara I, Powers DK, Krutz G. Comprehensive trachoma control program among the southwestern American Indians. Rev Int Trach 1971;47:53-64.

69 Liu B, Cowling C, Hayen A, et al. Relationship between community drug administration strategy and changes in trachoma prevalence, 2007 to 2013. PLoS Negl Trop Dis 2016;10:e0004810.

70 Ewald DP, Hall GV, Franks CC. An evaluation of a SAFE-style trachoma control program in central Australia. Med J Aust 2003;178:65-8.

71 Lange FD, Jones K, Ritte R, et al. The impact of health promotion on trachoma knowledge, attitudes and practice (KAP) of staff in three work settings in remote Indigenous communities in the Northern Territory. PLoS Negl Trop Dis 2017;11:e0005503.

72 Atkinson JR, Boudville AI, Stanford EE, et al. Australian football League clinics promoting health, hygiene and trachoma elimination: the Northern Territory experience. Aust J Prim Health 2014;20:334-8.

73 Lansingh VC, Mukesh BN, Keeffe JE, et al. Trachoma control in two central Australian Aboriginal communities: a case study. Int Ophthalmol 2010;30:367-75.

74 Mak DB, Plant AJ. Trichiasis in Aboriginal people of the Kimberley region of Western Australia. Clin Exp Ophthalmol 2001;29:7-11.

75 Peters MDJ, Godfrey CM, Khalil H, et al. Guidance for conducting systematic scoping reviews. Int J Evid Based Healthc 2015;13:141-6.

76 Mak DB, O'Neill LM, Herceg A, et al. Prevalence and control of trachoma in Australia, 1997-2004. Commun Dis Intell Q Rep 2006;30:236-47.

77 Baunach E, Lines D, Pedwel B. The development of culturally safe and relevant health promotion resources for effective trachoma elimination in remote Aboriginal communities. Aborig Is/ Health Work J 2012;36:9.

78 Napper G, Fricke T, Anjou MD, et al. Breaking down barriers to eye care for Indigenous people: a new scheme for delivery of eye care in Victoria. Clin Exp Optom 2015;98:430-4

79 Optometrists Association Australia A,. Torres Strait Islander eye health working $\mathrm{G}$. guidelines on the provision of sustainable eye care for Aboriginal and Torres Strait Islander Australians. Clin Exp Optom 2013;96:422-3.

80 Anjou MD, Boudville Al, Taylor HR. Why optometry must work from urban and regional Aboriginal health services. Clin Exp Optom 2012;95:615-7.
81 Boudville Al, Anjou MD, Taylor HR. Indigenous access to cataract surgery: an assessment of the barriers and solutions within the Australian health system. Clin Exp Ophthalmol 2013;41:148-54.

82 Taylor HR, Boudville Al, Anjou MD. The roadmap to close the gap for vision. Med J Aust 2012;197:613-5.

83 Indigenous Allied Health Australia. Cultural responsiveness in action: an IAHA framework, 2015. Available: https://iaha. com.au/workforce-support/training-and-development/culturalresponsiveness-in-action-training/

84 Arnold A-LMR, Busija L, Keeffe JE, et al. Use of eye care services by Indigenous Australian adults. Med J Aust 2011;194:537-8.

85 Huria T, Palmer SC, Pitama S, et al. Consolidated criteria for strengthening reporting of health research involving Indigenous peoples: the consider statement. BMC Med Res Methodol 2019;19:1-9.

86 Sugarman JR, Bauer MC, Barber EL, et al. Factors associated with failure to complete treatment for diabetic retinopathy among Navajo Indians. Diabetes Care 1993;16:326-8.

87 Boudville Al, Anjou MD, Taylor HR. Improving eye care for Indigenous Australians in primary health care settings. Aust J Rural Health 2013;21:121-7.

88 Wright HR, Keeffe JE, Taylor HR. Barriers to the implementation of the safe strategy to combat hyperendemic trachoma in Australia. Ophthalmic Epidemiol 2010;17:349-59.

89 Anjou MD, Boudville Al, Taylor HR. Correcting Indigenous Australians' refractive error and presbyopia. Clin Exp Ophthalmol 2013;41:320-8.

90 Abouzeid M, Anjou MD, Taylor HR. Equity in vision in Australia is in sight. Med J Aust 2015;203:21-3.

91 Tapp RJ, Anjou MD, Boudville Al, et al. The roadmap to close the gap for vision--diabetes-related eye care in the Indigenous Australian population. Diabet Med 2013;30:1145-6.

92 Anjou MD, Boudville Al, Taylor HR. Local co-ordination and case management can enhance Indigenous eye care--a qualitative study. BMC Health Serv Res 2013;13:255

93 Turner AW, Xie J, Arnold A-L, et al. Eye health service access and utilization in the National Indigenous eye health survey. Clin Exp Ophthalmol 2011;39:598-603.

94 Anjou M, Boudville A, Taylor $\mathrm{H}$. We can see the gap regional eye health coordination for Indigenous Australians. Aborig Islander Heal Work J 2012;36:12-16.

95 Silver K, Williams M, Macario E. The National eye health education program: increasing awareness of diabetic eye disease among American Indians and Alaska natives. Ethn Dis 2006;16:920-5.

96 Taylor HR, Anjou MD. Trachoma in Australia: an update. Clin Exp Ophthalmol 2013;41:508-12.

97 Hollows FC. Community-Based action for the control of trachoma. Rev Infect Dis 1985;7:777-82.

98 Shattock AJ, Gambhir M, Taylor HR, et al. Control of trachoma in Australia: a model based evaluation of current interventions. PLoS Negl Trop Dis 2015;9:e0003474

99 Hsueh Y-sengA, Dunt D, Anjou MD, et al. Close the gap for vision: the key is to invest on coordination. Aust $J$ Rural Health 2013;21:299-305

100 Martin JD, Yidegiligne HM. The cost-effectiveness of a retinal photography screening program for preventing diabetic retinopathy in the first nations diabetic population in British Columbia, Canada. Int J Circumpolar Health 1998;57 Suppl 1:379-82.

101 Optometrists Association Australia Aboriginal and Torres Strait Islander Eye Health Working Group. Guidelines on the provision of sustainable eye care for Aboriginal and Torres Strait Islander Australians. Clin Exp Optom 2013;96:422-3. 